\title{
MobRISK: a model for assessing the exposure of road users to flash flood events
}

\author{
Saif Shabou ${ }^{1}$, Isabelle Ruin ${ }^{1}$, Céline Lutoff ${ }^{2}$, Samuel Debionne ${ }^{1}$, Sandrine Anquetin ${ }^{1}$, Jean-Dominique Creutin ${ }^{1}$, and \\ Xavier Beaufils ${ }^{1}$ \\ ${ }^{1}$ Université Grenoble Alpes, CNRS, IGE, 38000 Grenoble, France \\ ${ }^{2}$ Université Grenoble Alpes, CNRS, PACTE, 38000 Grenoble, France
}

Correspondence to: Isabelle Ruin (isabelle.ruin@univ-grenoble-alpes.fr)

Received: 10 January 2017 - Discussion started: 14 March 2017

Revised: 17 July 2017 - Accepted: 11 August 2017 - Published: 25 September 2017

\begin{abstract}
Recent flash flood impact studies highlight that road networks are often disrupted due to adverse weather and flash flood events. Road users are thus particularly exposed to road flooding during their daily mobility. Previous exposure studies, however, do not take into consideration population mobility. Recent advances in transportation research provide an appropriate framework for simulating individual travelactivity patterns using an activity-based approach. These activity-based mobility models enable the prediction of the sequence of activities performed by individuals and locating them with a high spatial-temporal resolution. This paper describes the development of the MobRISK microsimulation system: a model for assessing the exposure of road users to extreme hydrometeorological events. MobRISK aims at providing an accurate spatiotemporal exposure assessment by integrating travel-activity behaviors and mobility adaptation with respect to weather disruptions. The model is applied in a flash-flood-prone area in southern France to assess motorists' exposure to the September 2002 flash flood event. The results show that risk of flooding mainly occurs in principal road links with considerable traffic load. However, a lag time between the timing of the road submersion and persons crossing these roads contributes to reducing the potential vehicle-related fatal accidents. It is also found that sociodemographic variables have a significant effect on individual exposure. Thus, the proposed model demonstrates the benefits of considering spatiotemporal dynamics of population exposure to flash floods and presents an important improvement in exposure assessment methods. Such improved characterization of road user exposures can present valuable information for flood risk management services.
\end{abstract}

\section{Introduction}

Flash flooding is considered one of the most dangerous natural hazard in terms of human losses. The rapidness and suddenness of this hydrometeorological phenomenon makes it hardly predictable and decreases the efficiency of rescue operations and the available time for people to protect themselves and to adapt their daily activities and mobility behaviors. Therefore, several vehicle-related accidents occur during flash floods. Death circumstances investigations showed that in postindustrial countries over half of flood victims are motorists trapped by road flooding (Ashley and Ashley, 2007; Sharif et al., 2012; Terti et al., 2017). Hence, daily mobility is pointed out as one of the primary causes of population exposure and vulnerability to flash floods (Ruin, 2010). However, mobility aspects are not systematically included in studies assessing human exposure and vulnerability to natural hazards. In order to integrate social vulnerability in risk measurement, population density data is often used assuming a static distribution, which contrasts with the fast dynamics of the flash flood phenomenon. Recently, it has progressively been acknowledged that variation of population distribution may provide a more accurate assessment of human exposure to natural hazards. Aubrecht et al. (2012) stressed the importance of including temporal variations of social vulnerability in every phase of the disaster management cycle. For instance, Freire and Aubrecht (2012) considered nighttime- and daytime-specific population densities for assessing population exposure to earthquake hazard in the Lisbon Metropolitan Area. Results showed that people are potentially at risk in the daytime period. In the context of flash floods, Terti et al. (2015, 2017) and Spitalar et al. (2014) showed that daily and sub-daily variation of population dis- 
tribution may provide an appropriate assessment of human exposure to such short-fuse weather events.

In fact, motorists' exposure to flood events is directly related to disruption and degradation of the road network. Road network studies use graph theory and more specifically directed graphs (called network) where the so-called edges or arcs represent the road segments linking the nodes or vertices corresponding to the road intersections. Several studies in transportation research focused on road network vulnerability to adverse weather conditions (Koetse and Rietveld, 2009; Transportation Research Board, 2008). Different methods were developed in order to identify critical road segments where disruptions would lead to severe consequences. Berdica (2002) defined road segment vulnerability as a function of the probability of occurrence of hazardous events and the importance of related impacts in terms of serviceability of road links. Jenelius et al. (2006) quantified the road network vulnerability by introducing the concept of criticality of the network constituents (e.g., link, node, groups of links and/or nodes), which includes both the probability of the constituents failing and the consequences of that failure for the system as a whole. Link criticalities depend on their weakness and their importance for the functioning of the whole network measured by the increased generalized travel cost when these links are closed.

Recently, Versini et al. (2010a) proposed a method for assessing road susceptibility to flooding in the Gard region (France) based on an inventory of observed flooded road sections over the last 40 years. The risk of road flooding is computed by combining susceptibility to flooding on a given road with simulated stream discharge of the corresponding river segment (Versini et al., 2010b). Naulin et al. (2013) extended the road flooding forecasting tool to the entire Gard region and proposed a method for allocating probabilities of flooding to road-river intersections (called "road cuts") depending on return periods of stream discharges (Naulin, 2012). Versini and Naulin's studies contribute to better forecasting the chance of road flooding, hence providing a strong base to further analyze the impact of road users' exposure.

To consider the risk for mobile people during flash flood there is a need to integrate travel-activity behaviors and individual responses to weather disruptions. Recently, impacts of extreme weather events on traffic flow and travel behaviors received much attention in transportation research (Böcker et al., 2013; Al Hassan and Barker, 1999; Koetse and Rietveld, 2009; Chung et al., 2005). Böcker et al. (2013) provided an extensive literature review on the potential impacts of weather on individual daily travel behaviors such as trip generation, travel destination and mode choices. Tsapakis et al. (2013) showed that high intensity of snow and rain decreases travel speed and increases travel time in the Greater London area. They also found that the impacts of weather conditions largely depend on drivers' attitudes, socioeconomic characteristics and other contextual factors. Andrey et al. (2013) investigated the effect of exposure frequency to adverse weather conditions on drivers' adaptation behaviors and concluded that drivers do not tend to acclimatize to local weather patterns. Based on a survey on travel decisions, Khattak and De Palma (1997) showed that adverse weather has a strong impact on travel decision changes such as route choice, transport mode choice and departure time.

These decisions partly depend on individual risk perception and personal evaluation of the environmental threat, which largely vary between individuals. Ruin et al. (2007) examined the effects of sociodemographic characteristics on perceived risk related to driving under heavy rain and through flooded roads. It was found that young male drivers have a clear tendency to underestimate the corresponding risk. Other factors seem to have a significant effect on mobility adaptation to flood events such as flood danger knowledge, flooding experience and route familiarity (Drobot et al., 2007; Ruin et al., 2009). In addition to risk perception, daily constraints related to professional and family activities are strong drivers of mobility regardless of the weather conditions (Ruin et al., 2007, 2014). The perceived importance and flexibility of planned and scheduled activities might play an important role in mobility adaptation capacities. Cools et al. (2010) demonstrated that travel change decisions related to weather conditions depend on trip purposes, with leisure and shopping activities being more likely to be canceled and postponed than work or school activities.

Thus, these findings highlight the relevance of considering both individual sociodemographic characteristics and daily activity schedules and constraints to establish an accurate assessment of population exposure to road flooding. Recent advances in mobility modeling following an activity-based approach offer an appropriate framework to microsimulate individual travel-activity patterns (Rasouli and Timmermans, 2014). These activity-based models consider travel behavior as derived from the demand of activity participation and aim at predicting the sequence of activities conducted by individuals (McNally, 1995). Activity-based models gain increasing interest in dynamic exposure assessment research, which is especially illustrated in air pollution exposure studies (Beckx et al., 2008, 2009; Pebesma et al., 2013) and homeland security applications (Henson et al., 2009). Flood exposure studies can also benefit from the wealth of information provided by this kind of mobility modeling approach. Indeed, the combination of individual travel-activity simulations with road flooding forecasts makes a thorough assessment of motorists' exposure and their evolution in time and space regarding the flood hazard possible.

In this paper we present the so-called MobRISK model, which aims at providing an assessment of motorists' exposure to flash floods by taking into account travel-activity behaviors and mobility adaptation with respect to weather disruptions and roads flooding. MobRISK is considered a microsimulation system since each individual of the population is represented individually, similarly to agent-based models (Gilbert, 2007). It is also an activity-based mobil- 
ity model in which the full individual travel-activity patterns are simulated. We illustrate the potential benefits of the proposed model through an application of MobRISK in the Gard region, which is a flash-flood-prone administrative area (French department) located in southern France. The objective of the proposed case study is to quantify motorists' exposure to the 8-9 September 2002 major flash flood event that resulting in 24 victims in the Gard area.

The remainder of the paper is organized as follows. The next section describes the conceptual modeling approach used in the MobRISK model. Section 3 details the required input data together with the description of the individual exposure measurement method. The case study area and results from MobRISK simulations are illustrated in Sect. 4. Finally, Sect. 5 discusses the results and provides insights for further research and potential improvements of the model.

\section{MobRISK modeling approach}

MobRISK is a model for assessing and simulating road users' exposure to road flooding due to extreme flash flood events by combining travel-activity simulations following an activity-based approach with hydrometeorological data. The MobRISK architecture includes (i) the simulated environmental changes considered for the study such as road flooding, (ii) an activity-based mobility model reproducing population travel-activity behaviors and (iii) a decision-making model predicting individual responses to weather disruptions. A discrete event simulator (DES) runs the main temporal loop of the simulations. In addition, the user input data is stored in a spatial relational database management system (Fig. 1).

\subsection{Discrete event simulation}

The core of the MobRISK simulator is a parallel discrete event simulator that runs the main temporal loop of the simulation. The pending event set is organized as a priority queue, sorted by event time and therefore handled in chronological order (Fujimoto, 1999; Robinson, 2004). Event-driven simulations are efficient in terms of computation time as they avoid unnecessary time steps. Four types of events are handled in MobRISK:

- road flooding: records different changes in probabilities of road flooding during a simulation period;

- environmental cue: reports the changes in environment and weather conditions that might be perceived by individuals such as precipitation intensities;

- broadcast: contains diverse warning and alert information that can be received by individuals and may affect their travel decisions; and

- travel activity: records changes of individual locations (at the road nodes resolution) and the travel purposes.

\subsection{Mobility modeling}

As explained in Sect. 1, to better understand and analyze mobility behaviors under environmental perturbations, we need to integrate daily travel motivations in the mobility modeling. Following an activity-based approach for mobility modeling, travel demand is considered to derive from the human need to perform different activities distributed in time and space (Recker et al., 1986). Recently, activity-based models have been gaining increasing attention due to the wealth of information they provide and the incorporation of behavioral and psychological components and decision-making processes.

The activity-based approach in travel modeling emerged in the 1970s as a complement to the concept of time geography of Hägerstrand (1970) and Chapin (1974), which introduced the importance of various spatial and temporal constraints on individuals' mobility behavior. While classical trip-based models, commonly referred to as "four step models", are focusing essentially on the quantification of trips generated by population mobility without considering the sequential characteristics and the behavioral dimension, activity-based models aim at predicting how, why, when, how often, where and with whom the different activities are conducted by the individuals (Bhat and Koppelman, 1999). McNally (1995) identified the most important specificities of activity-based modeling: (i) travel is derived from the demand for activity participation; (ii) sequences and patterns of travel behavior are the units of analysis instead of individual trips in trip-based models; (iii) household and sociodemographic characteristics affect travel-activity behavior; and (iv) spatial, temporal and interpersonal factors that constrain travel-activity patterns are taken into account.

Over the last years, several activity-based models have been developed: TRANSIMS (Smith et al., 1995), ALBATROSS (Arentze and Timmermans, 2000), CEMDAP (Bhat et al., 2004), MATSim (Balmer et al., 2006) and ADAPTS (Auld and Mohammadian, 2009). Although the mentioned models follow the same activity-based paradigm and provide useful frameworks for modeling individual motilities, they have some differences regarding the activity scheduling approach used, the decision-making process integration and the required input data structure. These differences depend essentially on research purposes and data availability.

Whereas the mentioned models are essentially applied for transport forecasting and urban planning, the main objective of MobRISK is to assess population mobility exposure to road flooding, which requires the combination of the travelactivity simulation with hydrometeorological data and road flooding impact data. Census data and travel-activity survey data are needed in order to assign daily activity programs to the population. Then, by locating the different activity areas, the population mobility is generated when individuals attempt to implement their activity programs. Finally, individual exposure over the flash flood event is defined by the prob- 


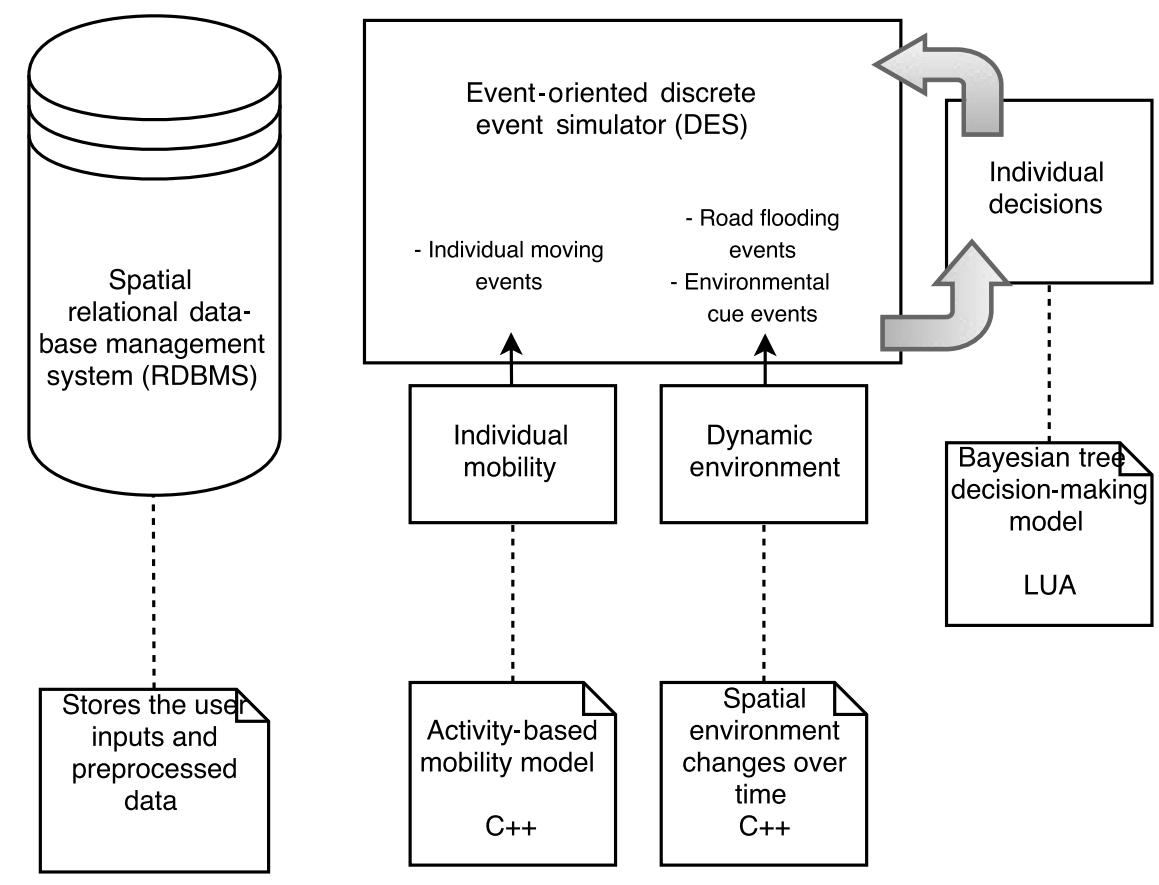

Figure 1. The MobRISK model architecture includes (i) the simulated environmental changes considered for the study such as road flooding, (ii) an activity-based mobility model reproducing population travel-activity behaviors and (iii) a decision-making model predicting individual responses to weather disruptions. A discrete event simulator (DES) runs the main temporal loop of the simulations. In addition, the user input data is stored in a spatial relational database management system.

ability (given the location and timing) of crossing flooded roads along each individual's route.

\section{Data and methods}

The MobRISK microsimulator was developed to measure the exposure of inhabitants and people working in the Gard administrative area, a region of southern France that has a long flash flood history. This region is characterized by a typical Mediterranean climate with heavy rainfall events during the autumn season (Delrieu et al., 2005; Gaume et al., 2009). In fact, since 1225, the Gard region suffered 506 floods. A total of $66 \%$ of the 353 municipalities experienced at least 10 referenced flood events and some of them were affected more than hundreds of times (CG30, 2016). Between 1316 and 1999, Antoine et al. (2001) recorded 27 fatal flood episodes and 277 deaths in Gard. Since 1999, five fatal events added about 30 casualties to the toll. In 2015, nearly $65 \%$ of the businesses and $35 \%$ of the population of the Gard area were located in a flood-prone zone.

In 2010, 726783 inhabitants were living in the Gard administrative area, which has a surface of $5852 \mathrm{~km}^{2}$. Among the 353 municipalities, 267 are essentially rural. Urban areas are mostly located next to Nîmes, the capital of the department consisting of 145501 inhabitants, and Alès (41 118 inhabitants; Fig. 2). The road network of the Gard region amounts to $12322 \mathrm{~km}$ of roads likely taken by commuters (paved roads), distributed between local roads ( $83.8 \%$ ), principal roads $(4.8 \%)$, regional roads $(10.3 \%)$ and highways $(1.1 \%)$. The river network is composed of 6443 river sections totaling $7087 \mathrm{~km}$ in length. Based on the work of Versini et al. (2010), a total of 1970 potential road cuts, which would be called "low-water crossing" in the USA, have been identified based on road-river intersections that are sensitive to flooding (see the detailed description in Sect. 3.2; Debionne et al., 2016). Even though the points exposed to flooding may be of three distinct types: river crossings, low accumulation points and river-adjacent points. Low-accumulation points and river-bordering points are much more difficult to identify as they are mostly due to very local settings that are not detectable on the digital terrain model (Versini et al., 2010). Therefore, those two types were not considered in Versini's work or in the study presented in this paper.

This section provides an overview of the required input data used in the MobRISK model. MobRISK makes maximum use of existing national databases, both geographical and social. SpatiaLiTE, the spatial extension of SQLiTe (a free relational database management system contained in the C programming library), is used extensively for input database building and preprocessing. The goal of input data preprocessing is to (i) identify the sociodemographic characteristics of individuals and households corresponding to the study area, (ii) attribute daily schedules to every individual and (iii) locate the areas where they are likely to conduct 


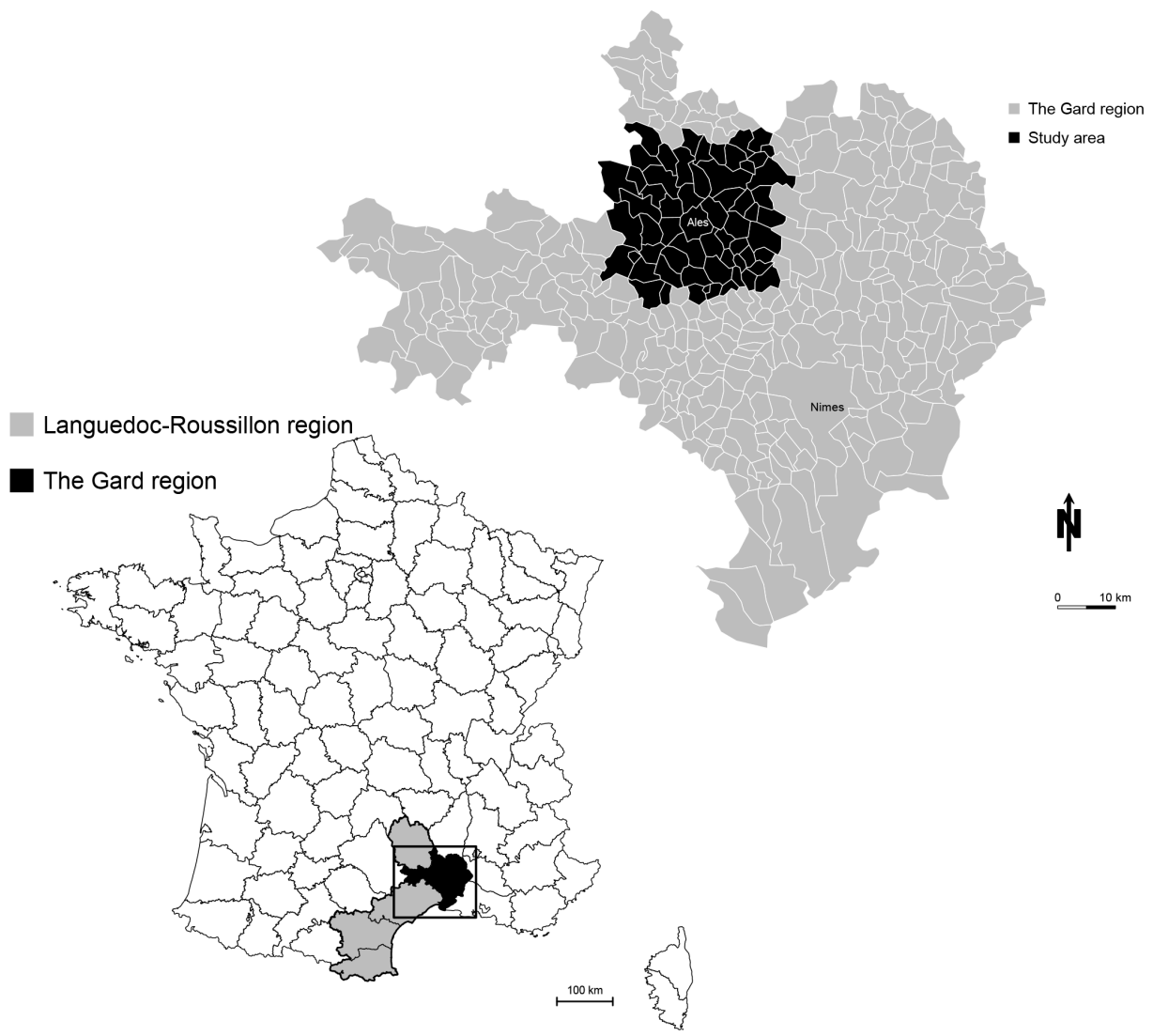

Figure 2. Maps of the study area with (i) the location of the Gard department (black) within the Languedoc-Roussillon region (grey) in France and (ii) the location of the 61 municipalities of the case study area among the 353 municipalities of the Gard department. Source: compiled by author from BD TOPO for regions' and municipalities' boundaries (http://professionnels.ign.fr/bdtopo).

their activities. Concerning the geographical data, road and river network data are used for identifying the vulnerability of road sections to flooding.

\subsection{Population data}

Sociodemographic description of the population is based on census data provided by Insee in 2010 (French National Institute of Statistics and Economic Studies). We use especially the INDCVI dataset, which contains the description of sociodemographic characteristics of the individuals, their household composition and household geographical location at the municipality resolution. In addition, we combine MOBPRO (professional mobility) and MOBSCO (student mobility) datasets issued from the Insee complementary exploration of census data. In addition to individual sociodemographics and household characteristics, these datasets describe individuals' commuting patterns. They include information about the municipalities of residence, work and school activities, traveled distances and usual commuting modes of professionals in five categories: (1) no transport; (2) on foot; (3) two-wheel vehicle; (4) car, truck and van; and (5) public transport. These data are stored into "individ- ual" and "household" tables and every individual is assigned to one household.

The description of individual activity schedules is based on travel-activity data, provided by the French National Transport and Travel Survey (ENTD) carried out by Insee from 2007 to 2008. In this survey, the responders were asked to indicate their sociodemographic characteristics (age, gender, professional status, etc.), their household composition and their mobility description during 1 weekday and 1 weekend. They were instructed to mention the different trips they made during the days of the survey, transport modes, trips' purposes, and time of departure and arrival. Based on these data, the individuals' schedules were retrieved, representing a sequence of activities mentioned by responders as trip purposes. Ten main activities are proposed in the survey: home, school, working, shopping, medical appointment, administrative procedure, visiting, accompanying persons, leisure and holiday activities.

The main objective of using the ENTD data is to assign daily schedules to the individuals described by the census data based on the effects of sociodemographic variables on schedules dissimilarities. The dissimilarities between sched- 
ules and pairs of sequences are measured by counting the number and type of operations needed to transform one sequence into the other (to match them). The operations considered are insertions, deletions or substitutions of activities. Figure 3 illustrates the matching of a pair of sequences in two different ways regarding the type of operation: (i) using only substitutions by replacing the different elements of one sequence with those in the second one and (ii) using a combination of insertion and deletion operations. The optimal matching (OM) distance metric allowing both substitutions and insertion/deletion of activities (Lesnard et al., 2011) is used in this study. Moreover, a method proposed by Studer et al. (2011) called the "discrepancy analysis" allows measuring the relationships between categorical variables (e.g., gender, age, education level, professional status) and a set of sequences described by the matrix of dissimilarities (measured with the OM method). It consists of measuring the pairwise dissimilarities between different activity sequences and implementing an ANOVA test to identify sociodemographic variables that explain the discrepancy of the sequences.

In addition to measuring the effect of sociodemographic variables on sequence dissimilarities, Studer et al. (2010, 2011) proposed a complementary regression tree analysis, which consists of a recursive partitioning of the sequences based on splitting criteria derived from the dissimilarity analysis. All individual activity sequences are grouped in the first node of the tree (root node). A discrepancy analysis is displayed to identify the variable explaining the greatest part of the sequence discrepancies. The sequences are then partitioned based on this variable in such a way that the resulting child ${ }^{1}$ nodes are as homogeneous as possible (with a low within dissimilarity). This operation is repeated recursively until no significant effect of sociodemographic variables is registered in the nodes' sequences. Hence, the schedule attribution rules can be extracted from the obtained tree with respect to the strength of relationships between sociodemographic characteristics and activity sequences. Then, every individual in the study area is connected to an average week schedule and an average weekend schedule based on these attribution rules. The proposed framework is implemented into a free package in R software called TraMineR (Gabadinho et al., 2011). Sequence discrepancy analysis methods have been especially used for exploring individual life trajectories (Studer et al., 2010; Widmer and Ritscard, 2009). Recent applications of sequence analysis methods on activity schedules and diary data have revealed the advantages of these approaches for capturing the complex structures of activity patterns and providing more accurate schedule classifications (Lesnard and Kan, 2011; Kim, 2014).

\footnotetext{
${ }^{1} \mathrm{~A}$ child node is a node directly connected to another node when moving away from the root node of the tree.
}

\subsection{Geographical data}

The next step in preprocessing the data for activity-based mobility modeling consists of locating the different areas where individuals might conduct their activities. Concerning housing activities, census data provide the municipality of residency of every household. In order to have a more precise spatial resolution, we use the RFL data (Revenus Fiscaux localisés - household localized taxes) published by Insee in 2010. The RFL data concerns the number of households and individuals living in them and their sociodemographic description provided at $200 \mathrm{~m} \times 200 \mathrm{~m}$ resolution for the entire French territory. Then, each household is located in the grid with respect to household densities by pixel. Concerning work and school activities, MOBPRO and MOBSCO datasets provide the municipalities' codes of both work and school places for workers and students. In order to enhance the spatial resolution, work and school places are assumed to be mostly located close to municipalities' administrative centers. Therefore, we assign a road node inside a buffer with a radius of $200 \mathrm{~m}$ around administrative centers of work and school municipalities to every worker and student. Finally, since we do not have reliable data for the locations of other activities (shopping, leisure, visiting, etc.), we randomly assign a road node inside a buffer of $500 \mathrm{~m}$ around the administrative center of every individual's municipality of residency.

The road network sensitivity to flooding is based on the connection of three datasets providing the description of the road and river networks and a list of the road sections susceptible to flooding called road cuts. Road network data is provided in the BD CARTO ${ }^{\circledR}$ database by the IGN (French National Mapping Agency), describing the road segments that compose the entire French road network by specifying their characteristics (regional, principal or local roads) and their locations in 2010. The second geographic information layer used refers to the river network provided by the BD CARTHAGE ${ }^{\circledR}$ database. It contains the different hydrographic segments and their attributes. The road cuts (low water crossings) dataset is derived from the intersection of river and road networks and calibrated using an inventory of road flooding during the last 40 years provided by the Gard road management services. Based on this dataset, Versini et al. (2010a) identified 1970 road cuts in the Gard road network and produced a classification of these road sections according to their susceptibility to flooding (Fig. 4). The four susceptibility classes range from $s_{0}$ to $s_{3}$, measuring 1093, 359, 297 and 221 points respectively. The "very low" susceptibility to flooding class $s_{0}$ corresponds to roadriver intersections that have empirical return periods of flooding exceeding 40 years. The "weak" $s_{1}$, "medium" $s_{2}$ and "high" $s_{3}$ susceptibility classes have an empirical flooding return period smaller than 1 year in 20,35 and $65 \%$ of their points respectively. Based on road cut classification, Naulin et al. (2013) developed a method to compute a probability of submersion for each road cut by combining the susceptibility 
(a) Using substitutions only

Sequence 1

\begin{tabular}{|l|l|l|l|l|} 
Home & Home & Home & Travel & Work \\
\hline
\end{tabular}

Sequence 2

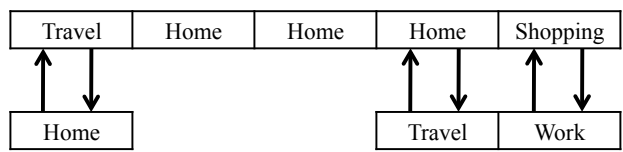

(b) Using insertions and deletions only

\begin{tabular}{|c|c|c|c|c|c|c|c|}
\hline Sequence 1 & & & Home & Home & Home & Travel & Work \\
\hline Sequence 2 & Travel & Home & Home & Home & Shopping & & \\
\hline
\end{tabular}

Figure 3. Schematic representation of sequence-matching operations. This figure illustrates the matching of a pair of sequences in two different ways regarding the type of operation: (a) using only substitutions by replacing the different elements of one sequence with those in the second one and (b) using a combination of insertion and deletion operations.

classes and simulated stream discharges at the section of river responsible for the road cut. Therefore, an interval of probability of submersion is assigned to every road cut for each combination susceptibility class and return period of stream discharge. In order to have one value of probability of submersion, the probability intervals are simplified in this study by considering the average value within interval probability limits (Table 1).

\subsection{Route choice and exposure measurement methods}

Once the different activities of each individual schedule are located and road section attributes are specified, the route selection criteria needs to be defined. Although various factors are involved in the route choice process, several studies indicated that minimizing travel time is the principal criterion for selecting routes (Papinski et al., 2009; Ramming, 2002; Bekhor et al., 2006). Therefore, we chose to use the classical Dijkstra algorithm - a single source shortest path algorithm that provides trees of minimal total length and time in a connected set of nodes (Dijkstra, 1959). The activity pattern attributions concern only the starting times and durations of the activities' sequences, which means that travel duration is computed based on the distance between the different activity locations for each individual. Therefore, the implemented schedules may be distorted compared to the assigned ones in terms of travel durations. Finally, motorists' exposure to road submersion can be measured based on the probability to encounter one or several flooded road cuts on their route during the simulated event period. The more important the probability of crossing submerged road cuts is, the higher the individual exposure is. Since individuals are likely to cross several road cuts with different probabilities of submersion, total exposure is computed by calculating the joint probability of submersion of all the crossed road cuts. The individual exposure index is calculated with the following Eq. (1):

$E($ ind $)=1-\prod_{k}\left(1-P\left(\operatorname{Sub}_{k}\right)\right)$,

where $E$ (ind) refers to the computed individual exposure and $P\left(\mathrm{Sub}_{k}\right)$ is the probability of submersion in the $k$ th road cut crossed. An example of exposure measurement is illustrated and explained in Fig. 5.

\section{Results}

Even though MobRISK model development is at the scale of the Gard department, we present in this section a first application of the model in the subregion of Alès located in the north of the Gard administrative area (Fig. 2).

\subsection{Case study}

The objective of this case study is to assess road users' exposure to road flooding during the 8-9 September 2002 event, which is considered to be one of the most catastrophic flash floods in the area since the one from 1958. In this first ap- 


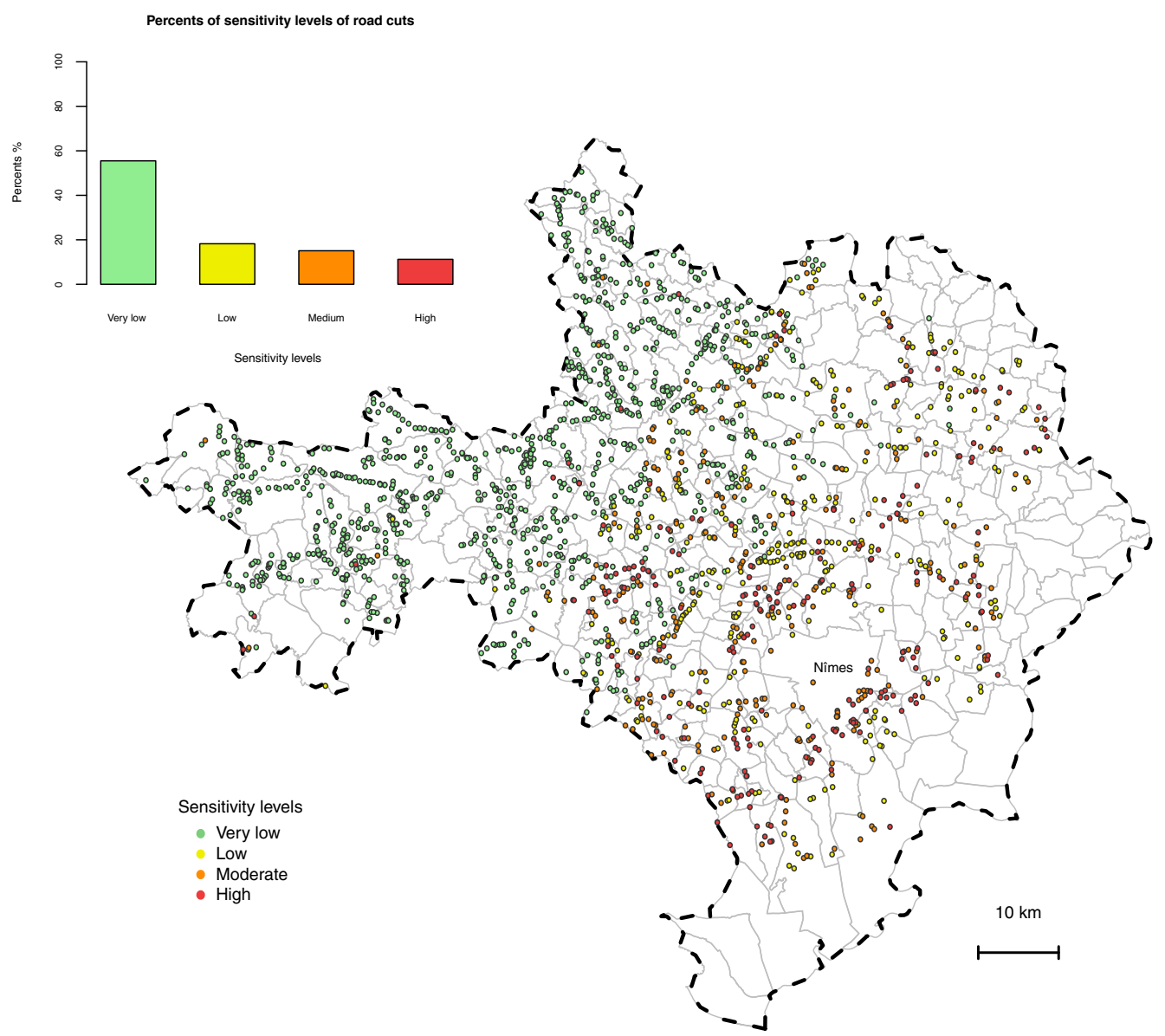

Sensitivity levels of road cut points

Figure 4. The spatial distribution of the 1970 road cuts identified in the Gard region with the different flooding susceptibility levels. The top-left bar plot represents the distribution of the road cuts (low water crossings) according to the 4 levels of flooding susceptibility. Source: compiled by author from BD CARTHAGE ${ }^{\circledR}$ for the hydrographic network (http://professionnels.ign.fr/bdcarthage), BD CARTO ${ }^{\circledR}$ for the road network (http://professionnels.ign.fr/bdcarto) and Versini et al. (2010a) for the road cut locations and susceptibility levels.

Table 1. Probabilities of submersion of the road cuts depending on the return periods of stream discharge, $Q$, and the susceptibility levels as defined by Naulin (2012) with the average values used in our case study.

\begin{tabular}{|c|c|c|c|c|c|c|c|c|}
\hline \multirow[b]{3}{*}{$\begin{array}{l}\text { Susceptibility } \\
\text { levels }\end{array}$} & \multicolumn{8}{|c|}{ Return periods } \\
\hline & \multicolumn{2}{|c|}{$Q_{2} / 2<Q<Q_{2}$} & \multicolumn{2}{|c|}{$Q_{2}<Q<Q_{10}$} & \multicolumn{2}{|c|}{$Q_{10}<Q<Q_{50}$} & \multicolumn{2}{|c|}{$Q>Q_{50}$} \\
\hline & $\begin{array}{r}\text { Probability } \\
\text { of submersion }\end{array}$ & $\begin{array}{r}\text { Utilized } \\
\text { value }\end{array}$ & $\begin{array}{r}\text { Probability } \\
\text { of submersion }\end{array}$ & $\begin{array}{r}\text { Utilized } \\
\text { value }\end{array}$ & $\begin{array}{r}\text { Probability } \\
\text { of submersion }\end{array}$ & $\begin{array}{r}\text { Utilized } \\
\text { value }\end{array}$ & $\begin{array}{r}\text { Probability } \\
\text { of submersion }\end{array}$ & $\begin{array}{r}\text { Utilized } \\
\text { value }\end{array}$ \\
\hline High & 0 to $67 \%$ & $33.5 \%$ & 67 to $100 \%$ & $83.5 \%$ & $100 \%$ & $100 \%$ & $100 \%$ & $100 \%$ \\
\hline Moderate & 0 to $33 \%$ & $16.5 \%$ & 33 to $57 \%$ & $45 \%$ & 57 to $61 \%$ & $59 \%$ & 61 to $100 \%$ & $80.5 \%$ \\
\hline Low & 0 to $20 \%$ & $10 \%$ & 20 to $34 \%$ & $27 \%$ & 34 to $35 \%$ & $34.5 \%$ & 35 to $100 \%$ & $67.5 \%$ \\
\hline Very low & $0 \%$ & $0 \%$ & $0 \%$ & $0 \%$ & $0 \%$ & $0 \%$ & 0 to $100 \%$ & $50 \%$ \\
\hline
\end{tabular}

plication, adaptation decisions generated by the decisionmaking model are not considered and we assume that individuals' travel plans do not change with the weather conditions and encountered flooded roads. The selected domain of this case study is composed of 61 municipalities around
Alès, which is the second largest municipality of the Gard region in terms of demography (Fig. 2). This first simulation provides an estimation of motorists' exposure to submersion based on their daily mobility for the Sunday and Monday of the 2002 flash flood event. During this event, the rainfall ac- 
Table 2. Description of the sociodemographic characteristics of the population in the case study area. Source: Insee (Census data, 2010, www.insee.fr)

\begin{tabular}{|c|c|c|}
\hline Variables & Groups & Percents $(\%)$ \\
\hline \multirow{2}{*}{ Gender } & Male & 47.76 \\
\hline & Female & 52.23 \\
\hline \multirow[t]{5}{*}{ Age } & $<18$ years old & 19.84 \\
\hline & $18-29$ years old & 10.62 \\
\hline & $30-45$ years old & 20.22 \\
\hline & $46-60$ years old & 21.78 \\
\hline & $>60$ years old & 27.52 \\
\hline \multirow[t]{4}{*}{ Education level } & No education & 33.06 \\
\hline & School - college & 39.1 \\
\hline & Bachelor & 13.07 \\
\hline & University & 14.77 \\
\hline \multirow{8}{*}{ Profession } & Farmers & 0.43 \\
\hline & Shop or business owners & 3.92 \\
\hline & Managers and academics & 3.72 \\
\hline & Manual laborers & 10.29 \\
\hline & Administrative, sales or service occupations & 9.41 \\
\hline & Technicians & 13.10 \\
\hline & Retired & 25.29 \\
\hline & Unemployed & 3.80 \\
\hline \multirow[t]{5}{*}{ Professional status } & Working & 34.10 \\
\hline & Student & 6.44 \\
\hline & Retired & 25.29 \\
\hline & Unemployed & 7.58 \\
\hline & Other situation & 21.26 \\
\hline \multirow[t]{3}{*}{ Size of household } & 1 person & 15.93 \\
\hline & 2 persons & 32.82 \\
\hline & $>2$ persons & 51.23 \\
\hline \multirow[t]{3}{*}{ Occupation status } & Owner & 60.33 \\
\hline & Lodger & 36.81 \\
\hline & Other status & 2.84 \\
\hline \multirow[t]{3}{*}{ Number of cars by household } & No car & 10.58 \\
\hline & 1 car & 42.33 \\
\hline & $>1$ car & 47.08 \\
\hline
\end{tabular}

cumulation exceeded $600 \mathrm{~mm}$ in $12 \mathrm{~h}$, causing 24 deaths and economic damages estimated at EUR 1.2 billion. A more detailed hydrometeorological description of this event is provided in Delrieu et al. (2005). In terms of human impacts and death circumstances, more than half of the victims were outside buildings and five of them were vehicle-related fatalities (Ruin et al., 2008). The flash flood event started on a Sunday evening, which might have limited the number of victims related to car driving accidents.

In order to evaluate daily mobility exposure to flash flood risk, the MobRISK output contains a record of the different road nodes crossed by the individuals on their route (including the road cuts), the time at which they passed these nodes and the individual exposure index (Eq. 1). The results are presented in three main sections: (i) results of population mobility simulation, (ii) analysis of road submersion risk, and (iii) analysis of population exposure to road submersion.

\subsection{Population mobility}

The study area resident population is 111511 individuals. An overview of the population sociodemographic characteristics is displayed in Table 2. As explained in Sect. 3.1, we used travel-activity data from the National Transport and Travel Survey to attribute programs of activities to the population in our study area. In order to respect the regional statistical representativeness of the survey sample and benefit from an extensive schedule library with satisfactory variability, we select travel-activity data corresponding to survey responders 


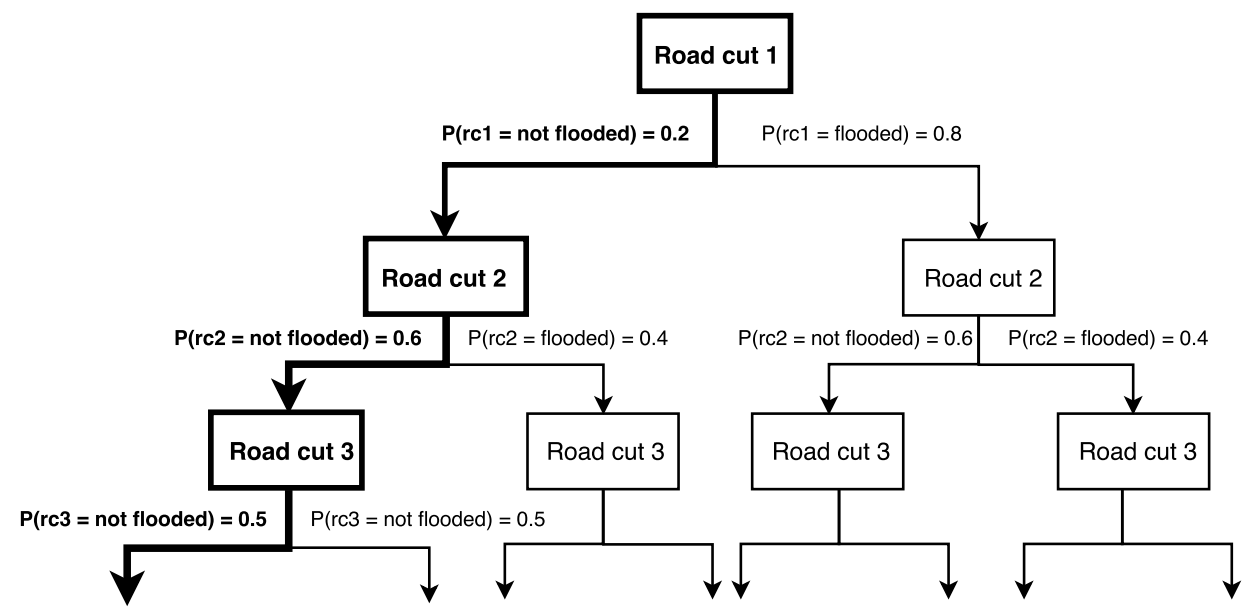

Figure 5. Probability tree diagram representing the method of measuring motorists' flood risk exposure. The highlighted (bold lines) path represents the example of a motorist who crossed 3 road cuts $(\mathrm{rc})$ with the following probabilities of submersion: $P\left(\mathrm{rc}_{1}=0.8\right), P\left(\mathrm{rc}_{2}=0.4\right)$ and $P\left(\mathrm{rc}_{3}=0.5\right)$. His/her exposure is represented as a probability tree diagram where the nodes are the encountered road cuts and the arcs represent the probability of submersion in each road cut as shown in the Figure. First, we calculate the probability that the driver does not cross a flooded rod cut, which corresponds to the product of probability of no submersion in the crossed road cuts: $P$ (not submerged road cuts $)=\left(1-P\left(\mathrm{rc}_{1}\right)\right) \cdot\left(1-P\left(\mathrm{rc}_{2}\right)\right) \cdot\left(1-P\left(\mathrm{rc}_{3}\right)\right)=0.06$. Then, the final exposure corresponds to $1-P($ not submerged road cuts $)=0.94$.

living in the Languedoc-Roussillon region (one of the 22 French Regions further divided into 5 "departments" including Gard). Since we are interested in motorists' exposure, only individuals using principally motorized transport modes are selected: representing 1240 weekday schedules and 1087 weekend schedules.

We conducted a multi-factor discrepancy analysis on the different schedules in order to assess the effect of sociodemographic variables on the activity sequence dissimilarities. We analyzed the effects of six variables: gender, age, education level, professional status, profession and household composition. The choice of these variables is based on previous studies on the effect of sociodemographic characteristics on daily travel-activity behavior (Pas, 1984). These variables are considered the independent variables, and the matrix of dissimilarities $\left(d_{i j}\right)$ between sequences are the dependent variables. Similar to the ANOVA test, individuals are grouped based on the selected factors and we attempt to compare the inter-group and intra-group variance to measure how much the chosen factors explain the total variance. The variance is then calculated based on Eq. (2), where the sum of squares (SS) is expressed using the average pairwise squared dissimilarities (Anderson, 2001):

$$
\begin{aligned}
\mathrm{SS} & =\sum_{i=1}^{n}\left(y_{i}-\bar{y}\right)^{2}=\frac{1}{2 n} \sum_{i=1}^{n} \sum_{j=1}^{n}\left(y_{i}-y_{j}\right)^{2} \\
& =\frac{1}{n} \sum_{i=1}^{n} \sum_{j=i+1}^{n} d_{\mathrm{ij}}^{2} .
\end{aligned}
$$

We observed that these selected variables explain $20 \%$ $\left(R^{2}=0.20\right)$ of the total discrepancy for the weekday sched- ules and only $3 \%\left(R^{2}=0.03\right)$ for weekend schedules (Table 3 ). Globally, there is a statistically significant effect of the selected variables on schedule discrepancy ( $p$ value $<0.05$ ). For an average weekday, the most significant variable is the professional status $(F=157530$ and $p<0.05)$. For the weekend, results indicate that the majority of the variables provide moderate but significant contributions to explain the total discrepancy, except gender, which is not significant $(F=4060, p>0.05)$.

We displayed a regression tree analysis generating 12 clusters for weekday schedules representing three classes of working men schedules (clusters 1, 2 and 3), three classes of working women schedules (clusters 4, 5 and 6), two classes of students (clusters 7 and 8) and four classes of non-working persons depending on their age and gender (clusters 9, 10, 11 and 12; Fig. 6a). For weekend schedules, the regression tree generated 10 clusters composed of a class of students (cluster 3), five classes of working persons depending on their household type and age (clusters 1, 2, 4, 5 and 6), and four classes of non-working persons depending on their age and household size (clusters 7, 8, 9 and 10; Fig. 6b). These results are used to produce "if-then" rules for assigning 1 weekday schedules and 1 weekend schedules to the individuals living in the study area. Each individual, according to his sociodemographic profile, is randomly assigned to one of the list of schedules corresponding to the appropriate cluster.

The MobRISK mobility model is implemented to simulate population mobility during 1 average weekend followed by an average weekday in order to simulate mobility patterns similar to the 8-9 September 2002 event, which happened to be a Sunday and a Monday. MobRISK generated in total 737135 trips in total: 333453 trips on Sunday and 403682 

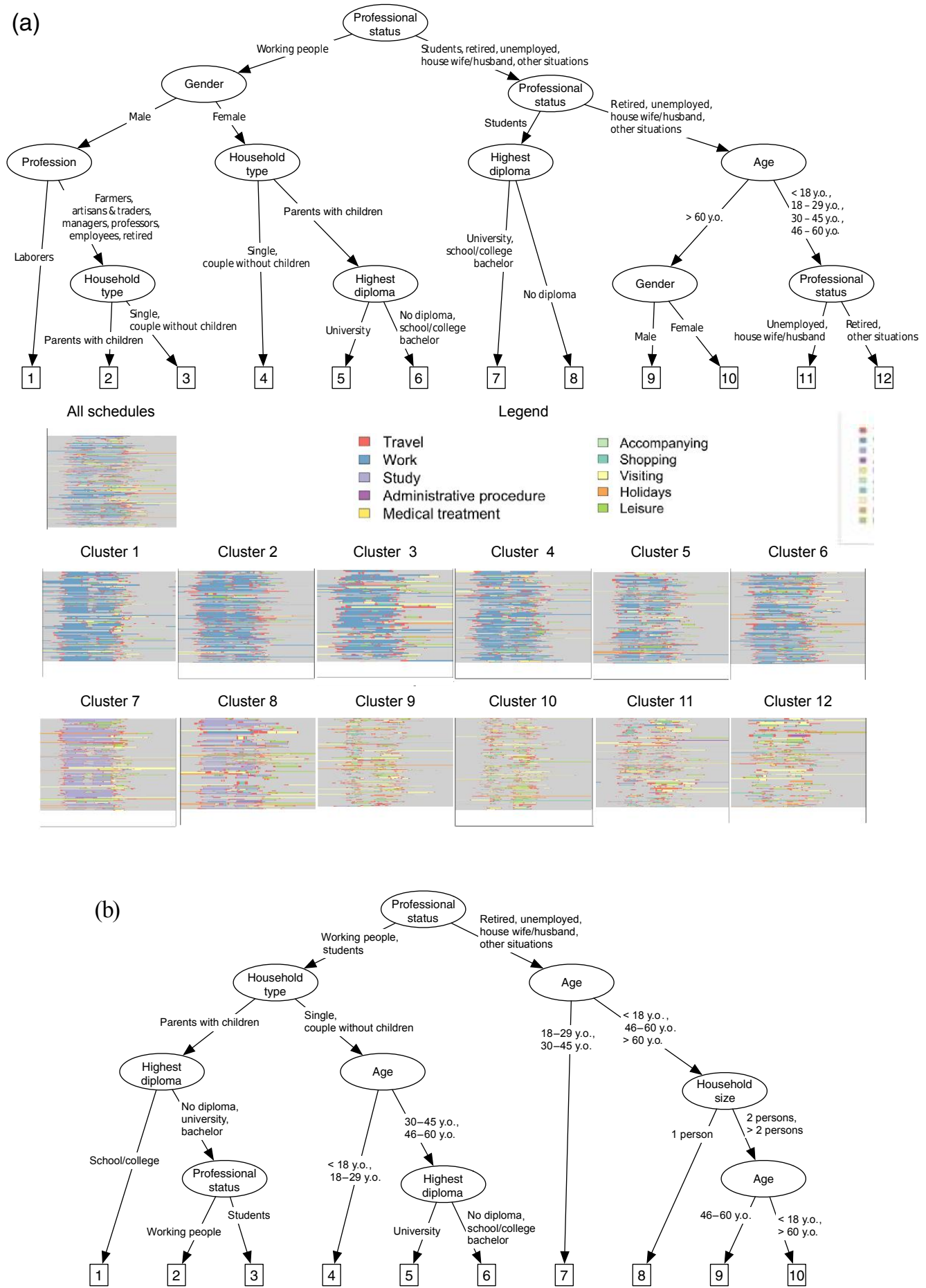

Figure 6. Regression tree results for weekday schedules (a) and weekend schedules (b) indicating 12 and 10 clusters of schedules respectively. The upper part of the figure displays the regression tree: each node represents the variable splitting the schedules into two groups and each arc represents the group/category. A visual representation of the weekday schedules corresponding to each cluster is displayed at the bottom of (a) each activity, represented by a color, and each line, representing a sequence of activities. 
Table 3. Results of the discrepancy analysis of activity sequences for each covariate in an average weekday and an average weekend. $\left(\mathrm{SS}_{T}\right)$ is the sum of all schedule pairwise distances divided by the number of schedules; $\left(\mathrm{SS}_{W}\right)$ is the sum of all schedule pairwise distances within groups divided by the number of schedules; $\left(R^{2}\right)$ refers to the part of the discrepancy explained by the variables; $(a)$ refers to the number of groups in each variables; $(N)$ is equal to $n(n-1) / 2$, where $n$ is the sample size. $R^{2}=\frac{\mathrm{SS}_{B}}{\mathrm{SS}_{\mathrm{t}}} ; F=\frac{\mathrm{SS}_{B} /(a-1)}{\mathrm{SS}_{W} /(N-a)}$. Formulas to calculate $F$ and $R^{2}$ for the total model are provided in Studer et al. (2011) and Anderson (2001).

\begin{tabular}{llrrr}
\hline Type of day & Variables & $F$ & $R^{2}$ & $p$ value \\
\hline Average weekday & Gender & 29308 & 0.005 & $0.001 * * *$ \\
& Age & 184434 & 0.113 & $0.001 * * *$ \\
& Education level & 33868 & 0.034 & $0.001 * * *$ \\
& Professional status & 157530 & 0.127 & $0.001 * * *$ \\
& Profession & 89305 & 0.103 & $0.001 * * *$ \\
& Household type & 7098 & 0.003 & $0.001 * * *$ \\
\hline Global & 33.64 & 0.203 & $0.01 * *$ & \\
\hline Average weekend day & Gender & 4060 & 0 & 0.079 \\
& Age & 19935 & 0.153 & $0.001 * * *$ \\
& Education level & 6819 & 0.007 & $0.001 * * *$ \\
& Professional status & 15923 & 0.016 & $0.001 * * *$ \\
& Profession & 10508 & 0.015 & $0.001 * * *$ \\
& Household type & 7316 & 0.004 & $0.001 * * *$ \\
\hline Global & & 3.96 & 0.033 & $0.001 * * *$ \\
\hline Significance level: $p<0.1 ; * *$ significance level: $p<0.05 ; * * *$ significance level: $p<0.01$.
\end{tabular}

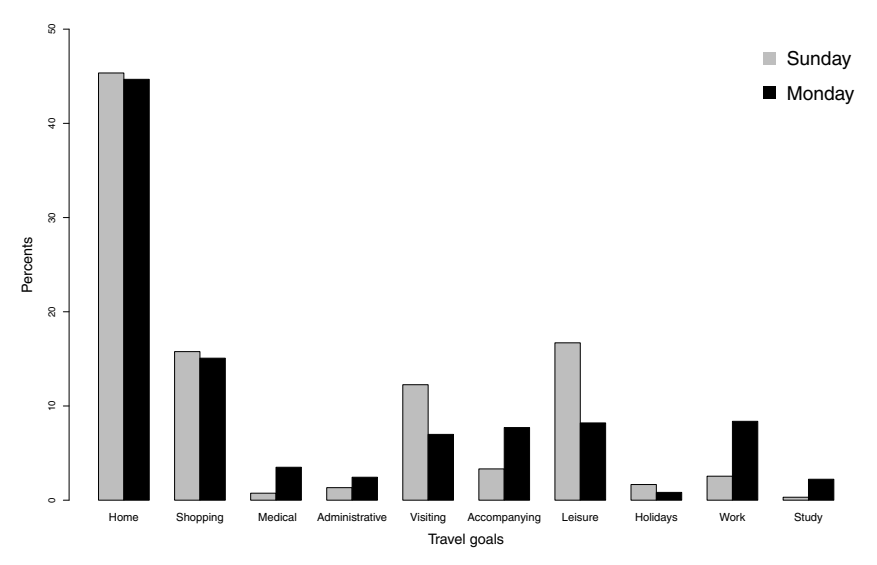

Figure 7. Distribution of simulated travel purposes between an average Sunday and an average Monday. Over the Alès case study area, 737135 trips were generated by the MobRISK model: 333453 trips on Sunday and 403682 on Monday.

on Monday. The average number of trips per individual was 3.06 on Sunday and 3.64 on Monday. When we examine the trip goals, we observe that more than $40 \%$ of individuals' trips are made to reach home. Obviously, the main difference between the weekdays and weekend in terms of trip goals is seen in the commuting trips, which are more important during weekdays, whereas visiting and leisure travels are more important during the weekend (Fig. 7).

\subsection{Road network sensitivity to flooding}

As mentioned in Sect. 3.2, a probability of submersion is assigned to every road cut by combining the flooding susceptibility level of the road section and the return period of stream discharge in the river section. The CVN (Cevenne) distributed hydrological model (Vannier et al., 2016; Branger et al., 2010; Viallet et al., 2006) is used to compute the discharge at the 738 road cuts identified in the Alès case study in hourly time steps for the 2002 flash flood. The CVN model is especially developed for simulating hydrological responses in flash flood events in the Cévennes region (south of France). Moreover, the implementation of the CVN model for reconstructing the 8 and 9 September 2002 event in the Gard region has provided satisfactory results (Braud et al., 2010; Anquetin et al., 2010). Discharge return periods are then computed at each road cut for hourly time steps and translated to submersion probabilities thanks to the relationship proposed by Naulin (2012, p. 93-94). Figure 8 shows that the period with the highest probability of road submersion takes place during the night of Sunday to Monday (89 September), leading to "weak" population exposure since less people are on the roads in the middle of a Sunday night. The spatial distribution of the simulated road submersion hazard for the whole flash flood event period, computed by summing up the hourly probabilities of flooding, shows a concentration of high flooding hazard in the south of the Alès municipality. 


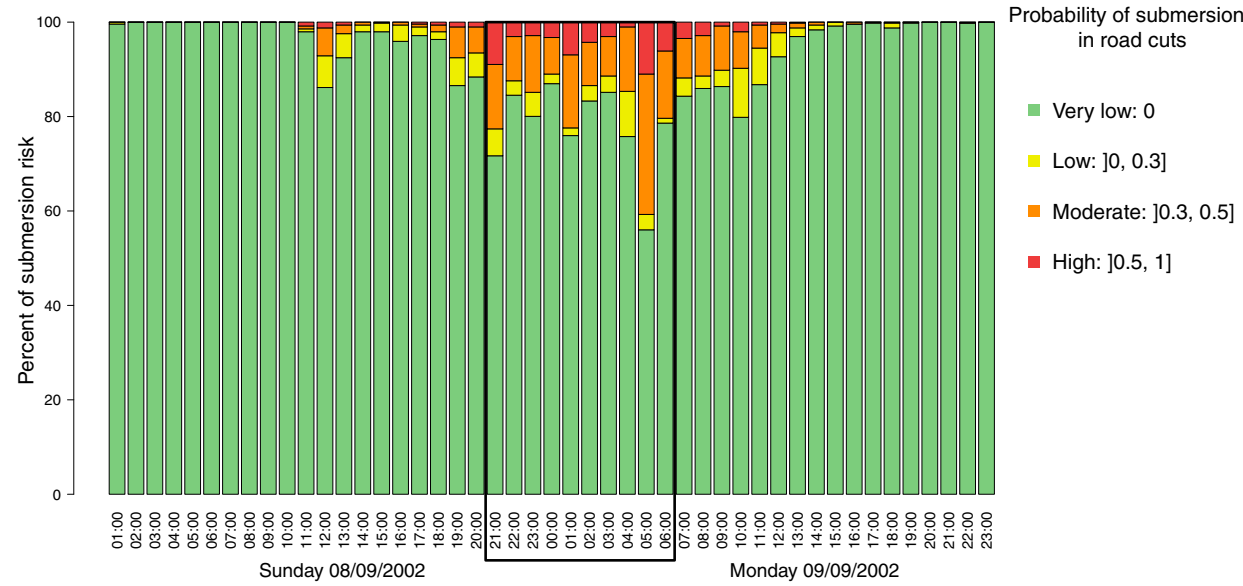

Figure 8. Temporal distribution of the simulated probability of submersion at road cuts. Results obtained by the simulation of the MobRISK model for the 8-9 September 2002 flash flood event in the Alès study area (Gard).

\subsection{Exposure analysis}

A first method for assessing road users' exposure to road flooding consists of quantifying the simulated traffic load in the potential road cuts identified in the study area during the 2 selected days. The computed exposure corresponds to the maximal exposure since the whole daily trips are assumed to be motorized. The results reveal that motorists were essentially exposed to road cuts corresponding to the two lowest levels of susceptibility (Table 4).

The spatial distribution of traffic load on potential road cuts shows a high motorist exposure on the main roads connecting Alès to the other major cities of the area: road D6110, road N106, road D981 and road D904 (Fig. 9). Figure 10 shows the dynamics of road users' exposure to potential road cuts represented by two peaks on Sunday, one at 10:00 local time (LT) and the other one at 16:00 LT, indicating, for the first peak, more than 25000 motorists crossing potential road cuts per hour. On Monday 9 September, three peaks are detected at 07:00 LT, 13:00 LT, and 16:00 LT, corresponding to commuting trips and reaching 40000 people crossing potential road cuts per hour. The comparison between temporal dynamics of roads submersion probabilities and traffic load in potential road cuts indicates a clear lag time between the period corresponding to high road submersion probabilities and the one with a larger number of exposed road users (Fig. 11). Indeed, this lag time is considered an important factor contributing to reducing vehicle-related accidents and fatalities for the 2002 flash flood event in this area.

This exposure measurement provides an estimation of traffic load on potential road cuts. Hence, by combining the flood hazard, represented by the hourly probabilities of submersion at road cuts, with human exposure, given by maximal traffic load passing these road cuts, it is possible to identify the number of persons who might have been endangered by crossing road cuts at the time they were submerged. The proposed risk index (Eq. 3) characterizes the number of motorists who could be in effective danger by multiplying the probability of submersion in road cuts with the number of motorists crossing them for every hour time step.

$$
\begin{gathered}
N\left(\operatorname{Ind}_{\text {danger }}\right)_{\mathrm{rc}, t}=\sum_{i}^{n_{\mathrm{rc}}} P(\text { submersion })_{\mathrm{rc}, t} \\
\cdot N\left(\operatorname{Ind}_{\text {exposed }}\right)_{\mathrm{rc}, t},
\end{gathered}
$$

where (rc) refers to the crossed road cut and $(t)$ is the time period.

In Fig. 11, the time evolution of the risk index reveals a different pattern from those associated with flooding hazard or with the traffic load at road cuts. The figure clearly illustrates that the period corresponding to the highest risk of flooding for road users occurred on 9 September from 05:00 LT to 11:00 LT with a peak at 07:00 LT, representing more than 1500 motorists $\mathrm{h}^{-1}$ in significant danger of flooding. The spatial distribution of the risk index determined for the whole event shows that the majority of road cuts presenting a considerable danger in terms of potential victims are located around the Alès municipality (Fig. 12). The results of the simulation for the entire event show that on average 15 individuals might have crossed dangerous road cuts. Geolocated vehicle-related fatal accident data provided by Ruin et al. (2008) are used as a first evaluation of this result. One vehicle-related victim (Fig. 12) was identified in our study area at a location that effectively corresponds to a road cut with high risk level (the 16th most dangerous road cut, $\left.N\left(\operatorname{Ind}_{\text {danger }}\right)=162\right)$. The proposed risk index mapping might thus provide an efficient indicator of flood risk magnitude in the road network since it combines both environmental and social parameters.

Finally, we investigate the effect of sociodemographic variables on individual exposure to road submersion. The MobRISK simulation of the probability, of each individual crossing submerged road sections on his daily route indi- 

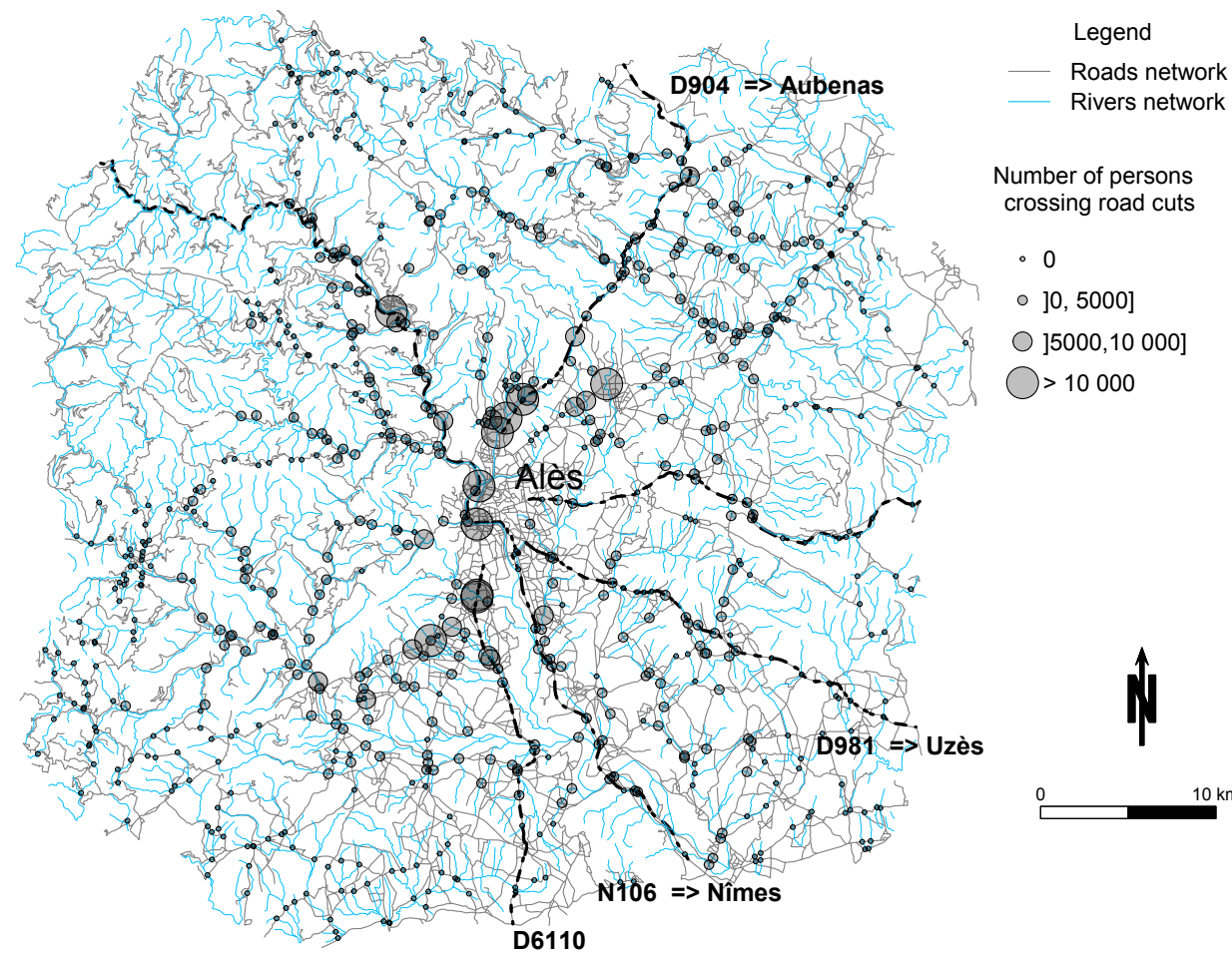

Number of persons

crossing road cuts

- 0

$\circ$ ]0, 5000]

] $] 5000,10000]$

$>10000$

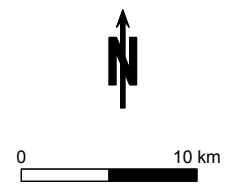

Figure 9. Spatial distribution of simulated traffic load at road cuts during the flash flood event period. Results obtained by the simulation of the MobRISK model for the 8-9 September 2002 flash flood event in the Alès study area (Gard).

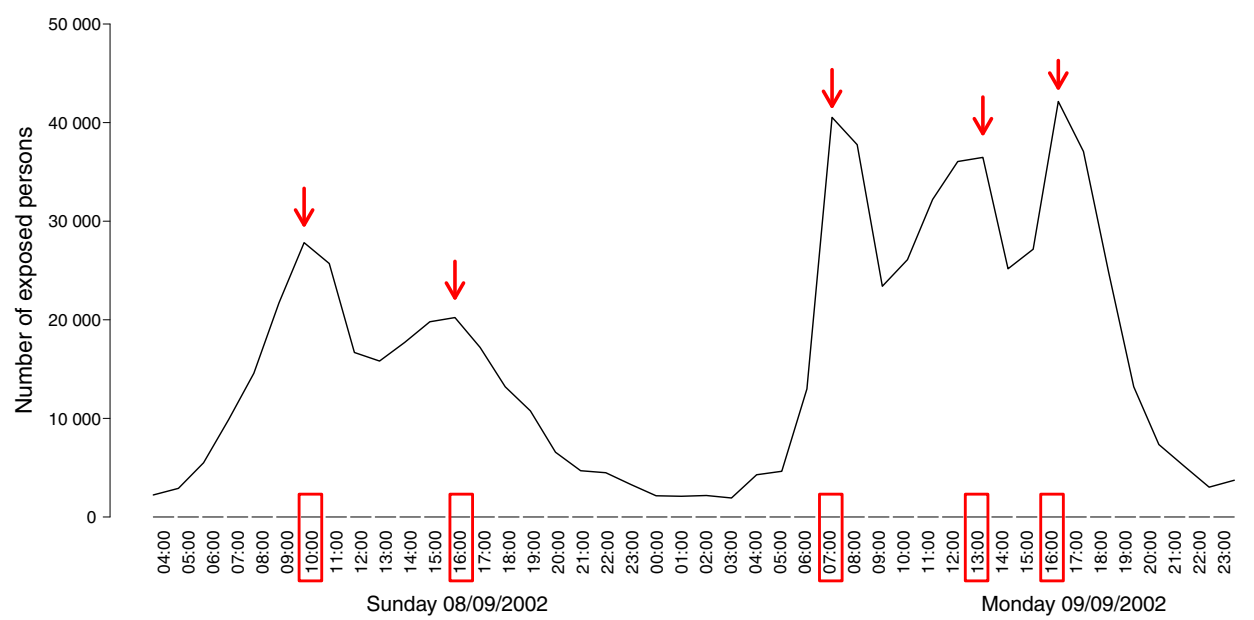

Figure 10. Temporal distribution of simulated traffic load at road cuts, which represent the hourly number of exposed persons. Results obtained by the simulation of the MobRISK model for the 8-9 September 2002 flash flood event in the Alès study area (Gard).

cates that the average individual exposure (Eq. 1) is 0.17 (a probability of $17 \%$ of crossing submerged roads during the event period) with a variance of 0.10 . A total of $75 \%$ of the road users have a zero risk of crossing submerged road cuts. Individual exposure varies with sociodemographic characteristics such as age, gender, professional status and profession. For instance, men are more exposed than women Exposure $_{\text {men }}=0.18$; Exposure $_{\mathrm{women}}=0.15$ ). Not surpris- ingly, workers are the most exposed, with an average risk of 0.28 , while retired and unemployed individuals have an average risk of 0.10. Managers, laborers and professors seem to be the most exposed professionals with an average exposure of 0.27 (Table 5). An analysis of variance (one-way ANOVA test) showed that the effects of the four selected variables are statistically significant (Table 6). The most exposed individuals are mainly young working males whose 
Table 4. Maximal number of motorists crossing potential road cuts during the event period (individuals can be counted several times if they crossed many road cuts in their itineraries).

\begin{tabular}{lrrrr}
\hline $\begin{array}{l}\text { Sensitivity levels } \\
\text { of road cuts }\end{array}$ & $\begin{array}{r}\text { Number of } \\
\text { road cuts }\end{array}$ & $\begin{array}{r}\text { Percent of road cuts } \\
\text { by sensitivity level (\%) }\end{array}$ & $\begin{array}{r}\text { Number of motorists } \\
\text { crossing road cuts (pers) }\end{array}$ & $\begin{array}{r}\text { Percent of motorists } \\
\text { crossing road cuts (\%) }\end{array}$ \\
\hline Very low & 523 & 70.87 & 327603 & 63.88 \\
Low & 103 & 13.96 & 81488 & 15.89 \\
Moderate & 75 & 10.16 & 98021 & 19.11 \\
High & 37 & 5.01 & 5742 & 1.12 \\
Total & 738 & 100 & 512854 & 100 \\
\hline
\end{tabular}

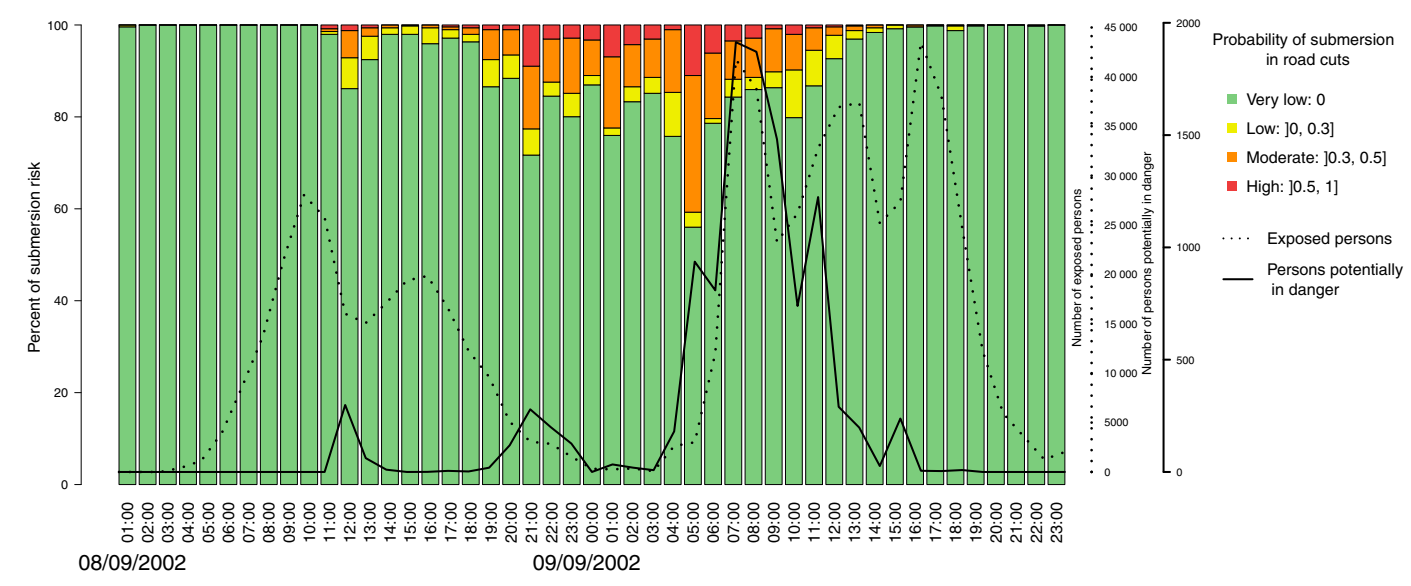

Figure 11. Time lag between the temporal distribution of the probability of submersion (colored bars) and the traffic load at road cuts (line). The dotted line represents the temporal distribution of the risk index referring to the number of persons potentially in danger (resulting from the combination of both the probabilities of submersion and traffic load). Results obtained by the simulation of the MobRISK model for the 8-9 September 2002 flash flood event in the Alès study area (Gard)

trips are generally more motorized and commute longer distances daily (Debionne et al., 2016). These results confirm the benefit of integrating mobility behaviors into social vulnerability assessment. This integration points out different socioeconomic vulnerability profiles that are usually not considered when dealing with static (resident) vulnerability. The classic static social vulnerability index usually attributes a high vulnerability level to women, elders and persons with low professional status (Cutter et al., 2000). These social profiles seem to be less exposed to road flash flooding.

\section{Discussion and perspectives}

The MobRISK microsimulator is to our knowledge the first of its kind in combining social and hydrometeorological state-of-the-art knowledge to understand the dynamics of human exposure and behavioral response to short-fuse weather events. This first implementation of MobRISK shows the potential of this tool for emergency planning and road management in crisis situations. Other examples of microsimulations often use a multi-agent platform to simulate such dynamic interactions (see for instance, Dawson et al., 2011) nevertheless those models do not allow addressing the scale of a French department (c.a. about $6000 \mathrm{~km}^{2}$ ) involving about 700000 agents. Because MobRISK has just recently been developed, several improvements are planned for improving its reliability, optimizing its functioning and moving toward a more operational tool.

The next step of its development is to better reproduce the travel durations observed in the ENTD dataset. In fact, the activity-based mobility modeling approach requires data describing the location of different activities conducted by the individuals. Whereas work and school activity locations are identified based on census data, it is more complicated to locate secondary activities such as shopping and leisure activities. We assume for this first application that secondary activities are located within a buffer of $500 \mathrm{~m}$ around the place of residency. However, future efforts are needed to improve the secondary activity location rules by taking into consideration travel costs and places knowledge (Marchal and Nagel, 2005). The buffer size used for secondary activity locations may affect the simulated travel durations. A comparison between simulated trip duration in MobRISK and observed trip duration retrieved from the ENTD data indicates an under estimation of simulated travel durations, corresponding especially to secondary activity travels (Fig. 13). This underes- 


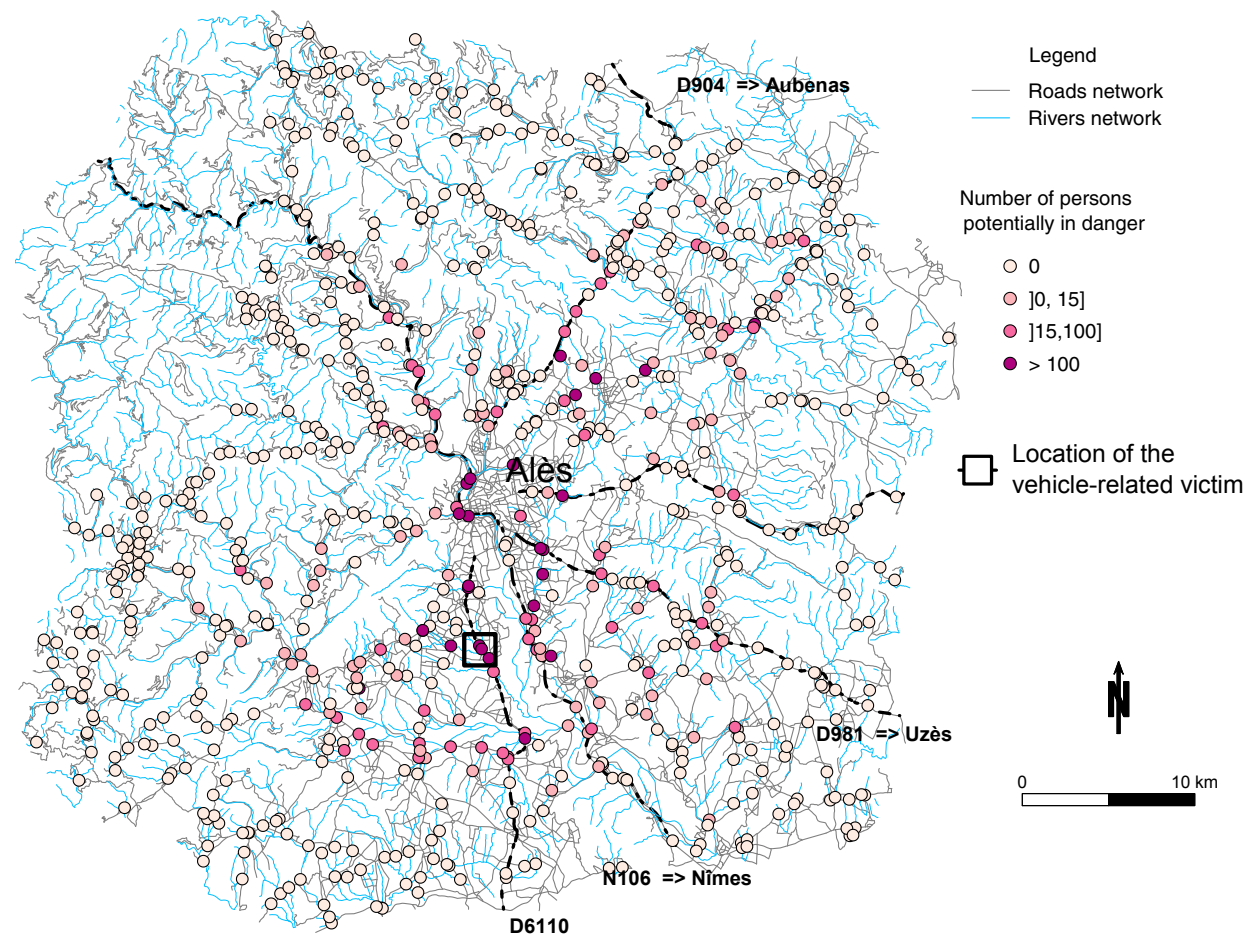

Figure 12. Spatial distribution of the risk index computed with the MobRISK simulator for the 8-9 September 2002 flash flood event in the Alès study area (Gard). It represents the potential number of endangered motorists who crossed flooded roads during the event period. The location of the past victim (black square) corresponds to a road cut with a high risk index.

Table 5. Motorists' exposure mean and standard deviation per sociodemographic characteristics. The bold numbers refer to the most exposed groups by variable.

\begin{tabular}{llrr}
\hline Variables & Groups & $\begin{array}{r}\text { Exposure } \\
\text { (mean) }\end{array}$ & $\begin{array}{r}\text { Exposure } \\
\text { (standard deviation) }\end{array}$ \\
\hline Gender & Male & $\mathbf{0 . 1 8}$ & 0.31 \\
& Female & 0.15 & 0.34 \\
\hline Age & <18 years old & 0.14 & 0.30 \\
& 18-29 years old & 0.21 & 0.36 \\
& 30-45 years old & $\mathbf{0 . 2 3}$ & 0.37 \\
& 46-60 years old & 0.20 & 0.35 \\
& > 60 years old & 0.11 & 0.26 \\
\hline Profession & Farmers & 0.16 & 0.32 \\
& Shop or business owners & 0.21 & 0.36 \\
& Managers and academics & $\mathbf{0 . 2 8}$ & 0.40 \\
& Manual laborers & $\mathbf{0 . 2 7}$ & 0.39 \\
& Administrative, sales or service occupations & $\mathbf{0 . 2 7}$ & 0.39 \\
& Technicians & 0.22 & 0.36 \\
& Retired & 0.10 & 0.25 \\
& Unemployed & 0.13 & 0.29 \\
\hline Professional status & Working & $\mathbf{0 . 2 8}$ & 0.39 \\
& Student & $\mathbf{0 . 2 2}$ & 0.36 \\
& Retired & 0.10 & 0.25 \\
& Unemployed & 0.10 & 0.26 \\
& House wife/husband & 0.09 & 0.25 \\
& Other situation & 0.12 & 0.26 \\
\hline
\end{tabular}



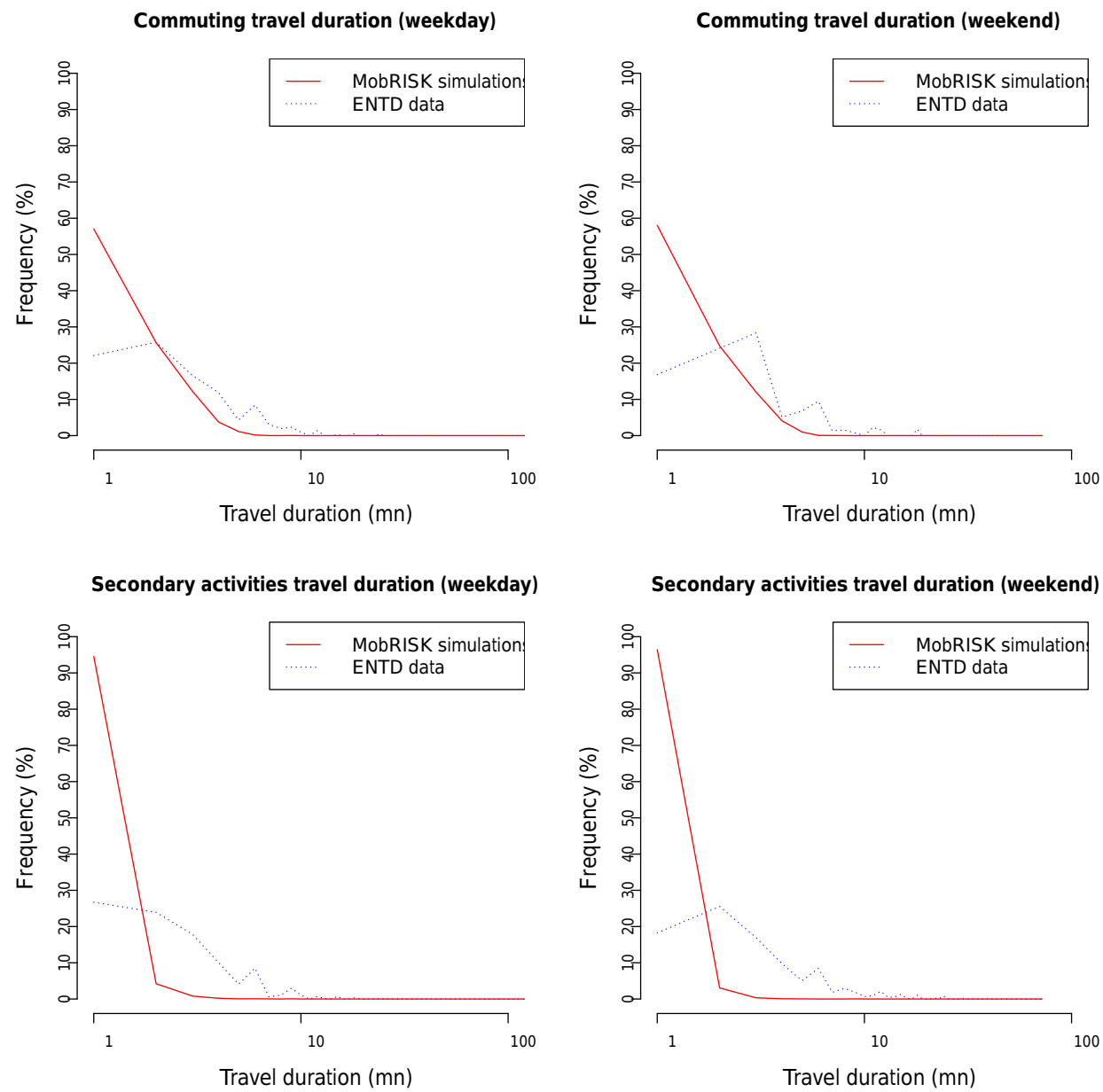

Figure 13. Comparison of travel duration distributions obtained from the MobRISK simulations and ENTD data for a weekday and a weekend and corresponding to commuting and secondary activity trips (we presented only trips with duration less than 60 min, which represents more than $94 \%$ of all the trips).

Table 6. Results of analysis of variance (ANOVA) for testing the effect of sociodemographic variables on individual submersion risk. Formulas to calculate the $F$ and $p$ value are provided in Anderson (2001).

\begin{tabular}{lll}
\hline Variables & & $p$ value \\
\hline Gender & $F(1,32637)=48.03$ & $0.00^{* * *}$ \\
Age & $F(4,32634)=166.5$ & $0.00^{* * *}$ \\
Professional status & $F(5,32633)=366.9$ & $0.00^{* * *}$ \\
Profession & $F(7,32631)=174.6$ & $0.00^{* * *}$ \\
\hline
\end{tabular}

* Significance level: $p<0.1 ; * *$ significance level: $p<0.05 ; * * *$ significance level: $p<0.01$.

timation may be explained by the buffer size selected for secondary activity location, which seems to be too small compared to the real size of activities' space and the shortest path criteria used for route choice. As a consequence, our model currently underestimates the computed motorist exposure.
Another important issue is the investigation of the link between exposure and human impact. The individual exposure measurement is merely defined as the probability of encountering flooded roads without taking into account the water height and flow level. This limitation is due to the difficulty in providing the necessary information because of the large number of parameters that need to be integrated regarding road infrastructures and geomorphologic specificities of road cuts. On the social side, understanding behavioral responses is key to the estimation of human impacts. Recently, this aspect has been taken into account in MobRISK, which now incorporates a decision-making module to consider possible activity rescheduling decisions and mobility adaptation to weather disruptions. The integration of individual decisions and coping capacities enables us to shift from exposure measurement to social vulnerability quantification (Terti et al., 2015). To advance in this direction, the use of welldescribed, geolocalized, time-stamped and reliable human 
impact datasets is needed for model verification (Terti et al., 2017).

While activity-based mobility models are using classical travel-activity pattern simulations, we opted for a schedule assignment method based on the effect of sociodemographics on activity sequence discrepancies. This choice is consistent with the main purpose of the MobiCLIMeX project, which aimed at understanding the driving forces of dynamic exposure over previous flash flooding events. Nevertheless, this tool could also be used to evaluate the longer-term evolution of human exposure related to climate change and its consequences in terms of extreme weather patterns. To move toward this direction, the module reproducing travel-activity patterns by schedule assignment would need to evolve toward the simulation of mobility scenarios.

In terms of implementations of MobRISK, the next step is to extend the simulation of the 8-9 September 2002 flash flooding event to the entire Gard area, as nearly all the municipalities of Gard were impacted by this event. Other less severe events with a different space-time distribution of rainfall may also be implemented to investigate the influence of the timing of the event on motorists' exposure.

\section{Conclusions}

This paper describes the MobRISK model, developed to capture the spatial-temporal dynamics of motorists' exposure to road submersion, in particular associated with flash flood hazard, for which fatalities are often vehicle related when water level and velocity cause a vehicle to be washed away. MobRISK is one of the first of its kind as it allows simulating the coupled dynamics of social and hydrometeorological processes at the scale of a French department of several thousands of square kilometers. The small temporal and spatial resolutions of the model (of the order of magnitude of the minute and the meter) allow an exploration of how flash floods impact and threaten people's daily schedule and mobility. The model's current application allows reproducing past flooding events in order to evaluate the variability of human exposure according to the distribution of rainfall and the timing of occurrence of the road flooding. MobRISK simulates individual mobility using an activity-based approach and individual exposure to road submersion and benefits from previous works and existing datasets characterizing road network sensitivity to flash floods in the Gard area. The first application of the MobRISK simulation over the Alès area for the period of the 8-9 September 2002 flash flood event offers the possibility of identifying the road sections bearing a higher risk for the population in time and space, both in terms of submersion probability and traffic load.

The results show that road submersion hazard was mainly located on principal roads connecting the Alès municipality to other major cities in the Gard area. The temporal analysis indicates that the highest road submersion hazards occurred at night at the end of a weekend, when traffic load is supposed to be lower. The simulation combining road submersion and individual mobility dynamics confirm this hypothesis and shows a clear lag time between traffic load patterns and road flooding. In order to take into account both hydrometeorological hazard and social exposure, a risk index is proposed by multiplying road submersion probability with the maximal number of motorists passing these roads.

The risk index helps to better characterize the spatiotemporal dynamics of population exposure to road submersion. Its output seems coherent with the location of the fatal vehicle-related accident that happened on Monday 9 September at 6 am within our study area. In fact, the road section where the accident occurred effectively shows one of the highest risk levels of the area. To further assess the performance of this model, a diverse and large amount of ground truth data would be needed. Fortunately, fatal accidents are extremely rare events. During flash flooding many dangerous situations are likely to emerge, although most events should hopefully end up happily with no casualties (Ruin et al., 2014). Geolocated and time-stamped data on traffic accidents, 911 calls, emergency safety operations or even social media observations would be very valuable for the assessment of such model.

This methodology also allows investigating the sociodemographic profiles of the most exposed people. The results highlight significant effects of some sociodemographic variables such as age, gender and professional activity. We show that young working males are clearly the most exposed to road flooding, which is coherent with analyses based on vehicle-related accidents in the USA (see for instance Terti et al., 2017).

The presentation of the model development and results to emergency and risk managers sheds light on their interest for such a dynamic approach and on the potential of this model for operational purpose. Identifying the hot spots of the road network associated with various hydrometeorological and vulnerability scenarios would indeed help, for instance, to prepare for flood crisis road management or to preposition emergency response teams. Another interest of such a tool is its potential ability to also address the exposure of people when they are not traveling. In fact, knowing about people's usual space-time mobility means that the model can also provide information about the exposure of people when they are not moving and spend time in flood-prone zones. Moving toward an operational tool that could eventually be used on near-real-time scenarios is one of our goals. We are planning to address it by enhancing our collaboration with scientists in the various domains of the model (meteorologists, hydrologists, psychologists and transport modelers) and operational stakeholders of warning response systems. 
Data availability. Data associated with this work are described in Sect. 3 and publicly available through data providers as INSEE (www.insee.fr), IGN (http: //professionnels.ign.fr/gratuite-des-donnees), OHMCV (http://ohmcv.osug.fr/spip.php?article30). Road cuts and road flooding susceptibility data were published in Versini et al. (2010a) and Naulin et al. (2012).

Competing interests. The authors declare that they have no conflict of interest.

Acknowledgements. The work developed in this paper was funded by the French national research agency ANR under two complementary projects ADAPTFlood and MobiCLIMeX respectively ANR-09-RPDOC-001-01 and ANR-12-SENV-0002-01. This work was also supported by the INSU through MISTRALS funding. It is part of the Hydrometeorological Experiment in the Mediterranean (HyMeX) initiative.

Edited by: Margreth Keiler

Reviewed by: two anonymous referees

\section{References}

Al Hassan, Y. and Barker, D. J.: The impact of unseasonable or extreme weather on traffic activity within Lothian Region, Scotland, J. Transp. Geogr., 7, 209-213, 1999.

Anderson, M. J.: A new method for Non-Parametric Multivariate Analysis of Variance, Austral Ecol., 26, 32-46, 2001.

Andrey, J., Hambly, D., Mills, B., and Afrin, S.: Insights into driver adaptation to inclement weather in Canada, J. Transp. Geogr., 28, 192-203, 2013.

Anquetin, S., Braud, I., Vannier, O., Viallet, P., Boudevillain, B., Creutin, J.-D., and Manus, C.: Sensitivity of the hydrological response to the variability of rainfall fields and soils for the Gard 2002 flash-flood event, J. Hydrol., 394, 134-147, 2010.

Antoine, J.-M., Desailly, B., and Gazelle, F.: Les crues meurtrières, du Roussillon aux Cévennes, Ann. Geogr., 622, 597-623, 2001.

Arentze, T. A. and Timmermans, H. J. P.: Albatross: A LearningBased Transportation Oriented Simulation System, European Institute of Retailing and Services Studies, Eindhoven, The Netherlands, 2000.

Ashley, S. T. and Ashley, W. S.: Flood Fatalities in the United States, J. Appl. Meteorol. Clim., 47, 805-818, 2008.

Aubrecht, C., Freire, S., Neuhold, C., Curtis, A., and Steinnocher, $\mathrm{K}$.: Introducing a temporal component in spatial vulnerability analysis, Disaster Advances, 5, 48-53, 2012.

Auld, J. A. and Mohammadian, A.: Framework for the development of the Agent-based Dynamic Activity Planning and Travel Scheduling (ADAPTS) model, Transportation Letters, The International Journal of Transportation Research 1, 243-253, 2009.

Balmer, M., Axhausen, K., and Nagel, K.: Agent-based demand modeling framework for large-scale micro-simulations, Transp. Res. Record, 1985, 125-134, 2006.
Beckx, C., Torfs, R., Arentze, T., Panis, L., Janssens, D., and Wets, G.: Establishing a dynamic exposure assessment with an activitybased modeling approach: methodology and results for the Dutch case study, Epidemiology, 19, S378-379, 2008.

Beckx, C., Panis, L., Arentze, T., Janssens, D., Torfs, R., and Broekx, S.: A dynamic activity-based population modelling approach to evaluate exposure to air pollution: methods and application to a Dutch urban area, Environ. Impact Assess., 29, 179185, 2009.

Bekhor, S., Ben-Akiva, M., and Ramming, M.: Evaluation of choice set generation algorithms for route choice models, Ann. Oper. Res., 144, 235-247, 2006.

Berdica, K.: An introduction to road vulnerability: what has been done, is done and should be done, Transp. Policy, 9, 117-127, 2002.

Bhat, C. R. and Koppelman, F. S.: Activity-based modeling of travel demand, in: The Handbook of Transportation Science, edited by: Hall, R. W., Kluwer Academic Publishers, Norwell, Massachusetts, 35-61, 1999.

Bhat, C. R., Guo, J. Y., Srinivasan, S., and Sivakumar, A.: A Comprehensive Econometric Microsimulator for Daily ActivityTravel Patterns, Transp. Res. Record, 1894, 57-66, 2004.

Böcker, L., Dijst, M., and Prillwitz, J.: Impact of Everyday Weather on Individual Daily Travel Behaviours in Perspective: A Literature Review, Transport Rev., 33, 71-91, 2013.

Branger, F., Braud, I., Debionne, S., Viallet, P., Dehotin, J., Henine, H., Nedelec, Y., and Anquetin, S.: Towards multi-scale integrated hydrological models using the LIQUID ${ }^{\circledR}$ framework: Overview of the concepts and first application examples, Environ. Model. Softw., 25, 1672-1681, 2010.

Braud, I., Roux, H., Anquetin, S., Maubourguet, M. M., Manus, C., Viallet, P., and Dartus, D.: The use of distributed hydrological models for the Gard 2002 flash flood event: Analysis of associated hydrological processes, J. Hydrol., 394, 162-181, 2010.

CG30: Population en zone inondable, Technical Report Conseil Général du Gard, available at: http://www.noe.gard.fr/index.php/ observatoire-du-risque-inondation/indicateurs?id=43, last access: 26 June 2016.

Chapin, F. S.: Human Activity Patterns in the City: Things People Do in Time and in Space, John Wiley and Sons, London, 1974.

Chung, E., Ohtani, O., Warita, H., Kuwahara, M., and Morita, H.: Effect of rain on travel demand and traffic accidents, in: Proceedings of the 8th International IEEE Conference on Intelligent Transportation Systems, Vienna, 2005.

Cools, M., Moons, E., Creemers, L., and Wets, G.: Changes in travel behavior in response to weather conditions: Do type of weather and trip purpose matter?, Transportation Research Record: Journal of the Transportation Research Board, 2157, 22-28, 2010.

Cutter, S. L., Mitchell, J. T., and Scott, M. S.: Revealing the vulnerability of people and places: A case study of Georgetown County, South Carolina, Ann. Assoc. Am. Geogr., 90, 713-737, 2000.

Dawson, R. J., Peppe, R., and Wang, M.: An Agent-based Model for Risk-based Flood Incident Management, Nat. Hazards, 59, 167-189, 2011.

Debionne, S., Ruin, I., Shabou, S., Lutoff, C., and Creutin, J. D.: Assessment of commuters' daily exposure to flash flooding over the roads of the Gard region, France, J. Hydrol., 541, 636-648, 2016. 
Delrieu, G., Ducrocq, V., Gaume, E., Nicol, J., Payrastre, O., Yates, E., Andrieu, H., Ayral, P.-A., Bouvier, C., Creutin, J.D., Livet, M., Anquetin, S., Lang, M., Neppel, L., Obled, C., Parent-du-Châtelet, J., Saulnier, G.-M., Walpersdorf, A., and Wobrock, W.: The catastrophic flash-flood event of 8-9 September 2002 in the Gard Region, France: A first case study for the Cévennes-Vivarais Mediterranean hydro-meteorological observatory, J. Hydrometeorol., 6, 34-52, 2005.

Dijkstra, E. W.: A note on two problems in connection with graphs, Numerical Mathematics, 1, 269-271, 1959.

Drobot, S. D., Benight, C., and Gruntfest, E. C.: Risk factors for driving into flooded roads, Environmental Hazards, 7, 227-234, 2007.

Freire, S. and Aubrecht, C.: Integrating population dynamics into mapping human exposure to seismic hazard, Nat. Hazards Earth Syst. Sci., 12, 3533-3543, https://doi.org/10.5194/nhess12-3533-2012, 2012.

Fujimoto, R. M.: Parallel and Distribution Simulation Systems, John Wiley \& Sons, Inc., New York, NY, USA, 1st Edn., 1999.

Gabadinho, A., Ritschard, G., Müller, N., and Studer, M.: Analyzing and Visualizing State Sequences in $\mathrm{R}$ with TraMineR, J. Stat. Softw., 40, 1-37, 2011.

Gaume, E., Bain, V., Bernardara, P., Newinger, O., Barbuc, M., Bateman, A., Blaskovicova, L., Bloschl, G., Borga, M., Dumitrescu, A., Daliakopouos, I., Garcia, J., Irimescu, A., Kohnova, S., Koutroulis, A., Marchi, L., Matreata, S., Medina, V., Preciso, E., Sempere-Torres, D., Stancalie, G., Szolgay, J., Tsanis, I., Velascom, D., and Viglione, A.: A compilation of data on European flash floods, J. Hydrol., 367, 70-78, 2009.

Gilbert, N.: Agent-based Models (Quantitative Applications in the Social Sciences), SAGE Publications, 2007.

Hägerstrand, T.: What about people in regional science?, Pap. Reg. Sci. Assoc., 24, 7-21, 1970.

Henson, K., Goulias, K., and Golledge, R.: An assessment of activity-based modeling and simulation for applications in operational studies, disaster preparedness, and homeland security, Transportation Letters, 1, 19-39, 2009.

Jenelius, E., Petersen, T., and Mattsson, L.-G.: Importance and exposure in road network vulnerability analysis, Transport. Res., 40, 537-560, 2006.

Khattak, A. J. and De Palma, A.: The impact of adverse weather conditions on the propensity to change travel decisions: a survey of Brussels commuters, Transport. Res., 31, 181-203, 1997.

Kim, K.: Discrepancy analysis of activity sequences: What Explains the Complexity of People's Daily Activity-Travel Patterns?, Transportation Research Record: Journal of Transportation Research Board, 2413, 24-33, 2014.

Koetse, M. J. and Rietveld, P.: The impact of climate change and weather on transport: an overview of empirical findings, Transport. Res. D-Tr. E., 14, 205-221, 2009.

Lesnard, L. and Kan, M. L.: Investigating scheduling of work: A two-stage optimal matching analysis of workdays and workweeks, J. Roy. Stat. Soc. A Stat., 174, 349-68, 2011.

Marchal, F. and Nagel, K.: Modeling location choice of secondary activities with a social network of cooperative agents, Transp. Res. Record, 1935, 141-146, 2005.

McNally, M. G.: An Activity-based Microsimulation Model for Travel Demand Forecasting, in: Activity-based Approaches to
Transportation Modeling, edited by: Ettema, D. and Timmermans, H., Elsevier, 1995.

Naulin, J. P.: Modelisation hydrologique distribueie pour la prevision des coupures de routes par inondation, Application au département du Gard, PhD Thesis, Ecole Centrale de Nantes, IFSTTAR, FRANCE, 2012.

Naulin, J. P., Payrastre, O., and Gaume, E.: Spatially distributed flood forecasting in flash flood prone areas: Application to road network supervision in Southern France, J. Hydrol., 486, 88-99, 2013.

Papinski, D., Scott, D. M., and Doherty, S. T.: Exploring the route choice decision-making process: A comparison of planned and observed routes obtained using person-based GPS, Transport. Res. F-Traf., 12, 347-358, 2009.

Pas, E. I.: The Effect of Selected Sociodemographic characteristics on daily travel-Activity Behavior, Environ. Plann. A, 16, 571581, 1984.

Pebesma, E., Helle, K., Christoph, S., Rasouli, S., Timmermans, H., Walker, S. E., and Denby, B.: Uncertainty in exposure to air pollution, EGU General Assembly Conference Abstracts, Vol. 15, p. 8362, EGU General Assembly 2013, Vienna, Austria, 2013.

Ramming, S.: Network knowledge and route choice, PhD Thesis, Massachusetts Institute of Technology, Cambridge, USA, 2002.

Rasouli, S. and Timmermans, H.: Activity-based models of travel demand: promises, progress and prospects, Int. J. Urban Sci., 18, 31-60, 2014.

Recker, W. W., McNally, M. G., and Root, G. S.: A model of complex travel behavior: part I. Theoretical development, Transport. Res. A-Pol., 20, 307-318, 1986.

Robinson, S.: Simulation - The practice of model development and use, Chichester, Wiley, 2004.

Ruin, I.: Conduite à contre-courant et crues rapides, le conflit du quotidien et de l'exceptionnel, Ann. Geogr., 674, 419-432, 2010.

Ruin, I., Gaillard, J. C., and Lutoff, C.: How to get there? Assessing motorists' flash flood risk perception on daily itineraries, Environmental Hazards, 7, 235-244, 2007.

Ruin, I., Creutin, J.-D., Anquetin, S., and Lutoff, C.: Human exposure to flash floods - Relation between flood parameters and human vulnerability during a storm of September 2002 in Southern France, J. Hydrol., 361, 199-213, 2008.

Ruin, I., Creutin, J. D., Anquetin, S., Gruntfest, E., and Lutoff, C.: Human vulnerability to flash floods: addressing physical exposure, in: Flood risk management: research and practice, edited by: Samuels, P., Huntington, S., Allsop, W., and Harrop, J., Taylor and Francis, London, 1005-1012, 2009.

Ruin, I., Lutoff, C., Boudevillain, B., Creutin, J. D., Anquetin, S., Bertran Rojo, M., Boissier, L., Bonnifait, L., Borga, M., Colbeau-Justin, L., Creton-Cazanave, L., Delrieu, G., Douvinet, J., Gaume, E., Gruntfest, E., Naulin, J. P., Payrastre, O., and Vannier, O.: Social and hydrological responses to extreme precipitations: an interdisciplinary strategy for postflood investigation, Weather Clim. Soc., 6, 135-153, 2014.

Sharif, H. O., Hossain, M. M., Jackson, T., and Bin-Shafique, S.: Person- place-time analysis of vehicle fatalities caused by flash floods in Texas, Geomatics, Natural Hazards and Risk, 3, 311323, 2012.

Smith, L., Beckman, R., and Baggerly, K.: TRANSIMS: Transportation analysis and simulation system (No. LA-UR-95-1641), Los Alamos National Lab, NM, United States, 1995. 
Spitalar, M., Gourley, J. J., Lutoff, C., Kirstetter, P., Brilly, M., and Carr, N.: Analysis of flash flood parameters and human impacts in the US from 2006 to 2012, J. Hydrol., 519, 863-870, 2014.

Studer, M., Ritschard, G., Gabadinho, A., and Müller, N. S.: Discrepancy analysis of complex objects using dissimilarities, in: Advances in Knowledge Discovery and Management, edited by: Guillet, F., Ritschard, G., Zighed, D. A., and Briand, H., volume 292 of Studies in Computational Intelligence, Berlin, Springer, 3-19, 2010.

Studer, M., Ritschard, G., Gabadinho, A., and Müller, N. S.: Discrepancy analysis of state sequences, Sociol. Meth. Res., 40, 471-510, 2011.

Transportation Research Board: Potential impacts of climate change on US transportation (TRB Special Report 290), Washington, DC, 2008.

Tsapakis, I., Cheng, T., and Bolbol, A.: Impact of weather conditions on macroscopic urban travel times, J. Transp. Geogr., 28, 204-2011, 2013.

Terti, G., Ruin, I., Anquetin, S., and Gourley, J. J.: Dynamic vulnerability factors for impact-based flash flood prediction, Nat. Hazards, 79, 1481-1497, 2015.

Terti, G., Ruin, I., Anquetin, S., and Gourley, J. J.: A Situationbased Analysis of Flash Flood Fatalities in the United States, B. Am. Meteorol. Soc., 98, 333-345, 2017.
Vannier, O., Anquetin S., and Braud, I.: Investigating the role of geology in the hydrological response of Mediterranean catchments prone to flash-floods: regional modelling study and process understanding, J. Hydrol., 541, 158-172, https://doi.org/10.1016/j.jhydrol.2016.04.001, 2016.

Versini, P.-A., Gaume, E., and Andrieu, H.: Assessment of the susceptibility of roads to flooding based on geographical information - test in a flash flood prone area (the Gard region, France), Nat. Hazards Earth Syst. Sci., 10, 793-803, https://doi.org/10.5194/nhess-10-793-2010, 2010a.

Versini, P.-A., Gaume, E., and Andrieu, H.: Application of a distributed hydrological model to the design of a road inundation warning system for flash flood prone areas, Nat. Hazards Earth Syst. Sci., 10, 805-817, https://doi.org/10.5194/nhess-10-8052010, 2010b.

Viallet, P., Debionne, S., Braud, I., Dehotin, J., Haverkamp, R., Saadi, Z., Anquetin, S., Branger, F., and Varado, N.: Towards multi-scale integrated hydrological models using the LIQUID framework, in: 7th International Conference on Hydroinformatics 2006, 4-8 September, Nice, France, 1, 542-549, 2006.

Widmer, E. D. and Ritschard, G.: The de-standardization of the life course: Are men and women equal?, Adv. Life Course Res., 14, 28-39, 2009. 